\title{
Dental development and age at death of the holotype of Anapithecus hernyaki (RUD 9) using synchrotron virtual histology
}

\author{
Adeline Le Cabec ${ }^{a, b}{ }^{*}$, M. Christopher Dean ${ }^{c}$, David R. Begun d \\ a Department of Human Evolution, Max Planck Institute for Evolutionary Anthropology, Deutscher Platz 6, D-04103, Leipzig, \\ Germany \\ b Beamline ID19, Structure of Materials, ESRF - The European Synchrotron, 71, avenue des Martyrs, CS 40220, F-38043, \\ Grenoble, Cedex 9, France \\ c Department of Cell and Developmental Biology, University College London, Gower Street, London, WC1E 6BT, UK \\ d Department of Anthropology, University of Toronto, Toronto, ONT M5S 3G3, Canada
}

\begin{abstract}
The chronology of dental development and life history of primitive catarrhines provides a crucial comparative framework for understanding the evolution of hominoids and Old World monkeys. Among the extinct groups of catarrhines are the pliopithecoids, with no known descendants. Anapithecus hernyaki is a medium-size stem catarrhine known from Austria, Hungary and Germany around $10 \mathrm{Ma}$, and represents a terminal lineage of a clade predating the divergence of hominoids and cercopithecoids, probably more than $30 \mathrm{Ma}$. In a previous study, Anapithecus was characterized as having fast dental development. Here, we used non-destructive propagation phase contrast synchrotron micro-tomography to image several dental microstructural features in the mixed mandibular dentition of RUD 9, the holotype of $A$. hernyaki. We estimate its age at death to be 1.9 years and describe the pattern, sequence and timing of tooth mineralization. Our results do not support any simplistic correlation between body mass and striae periodicity, since RUD 9 has a 3-day periodicity, which was previously thought unlikely based on body mass estimates in Anapithecus. We demonstrate that the teeth in RUD 9 grew even faster and initiated even earlier in development than suggested previously. Permanent first molars and the canine initiated 49 and 38 days prenatally, respectively. These results contribute to a better understanding of dental development in Anapithecus and may provide a window into the dental development of the last common ancestor of hominoids and cercopithecoids.
\end{abstract}

\section{Keywords}

Late Miocene, Stem catarrhine, Eruption pattern, Cuspal daily secretion rate, Virtual anthropology, Life history

\section{Introduction}

Much research on dental development has focused on fossil hominoids and other extant primates, while stem catarrhines remain poorly studied. New non-destructive imaging techniques have now made it possible to study the microanatomy of fossil enamel and dentine (Tafforeau et al., 2006; Zabler et al., 2006; Smith et al., 2010a). This in turn enables us to reconstruct the chronology of enamel development and the timing and sequence of tooth initiation in the jaws of fossil specimens that would other- wise be impossible without resorting to destructive techniques (T.M. Smith et al., 2015). Understanding more about dental development in primitive catarrhines, such as the pliopithecoid Anapithecus, provides important background for the study of extant and extinct crown taxa. This in turn will eventually contribute to defining the ancestral condition and the polarity of characters that can be used in phylogenetic analyses.

Catarrhines are estimated to have originated during the late Oligocene, $32.1 \mathrm{Ma}$ (95\% highest posterior density confidence interval 1/4 29.4e33.8 Ma) based on mtDNA evidence (Pozzi et al., 2014). The divergence of the hominoids (apes) and cercopithecoids (Old World monkeys [OWM]) is estimated to be between 23 and 28 Ma (Steiper and Seiffert, 2012; Harrison, 2013; Raaum, 2015). Pliopithecoids have no extant descendants, precluding a divergence date based on DNA. However, since pliopithecoids are catarrhines but lack derived characters shared by OWM 
and apes, their appearance must predate the divergence of OWM and apes. Therefore, and from the two ranges of time previously cited, the origin of pliopithecoids can be estimated to have occurred between $\sim 23$ and 32 Ma. Geographically, the pliopithecoids range from Western Europe to China. They first appear in the fossil record at about 18 Ma in China (Harrison et al., 1991; Begun, 2002). So there is a gap in the fossil record of pliopithecoids of at least $5 \mathrm{Ma}$ and possibly as much as 13 Ma. Anapithecus hernyaki is among the later occurring species of pliopithecoid, dated to about $10 \mathrm{Ma}$ (Kordos and Begun, 2001). It is known from a few specimens recovered from the sites of Salmendingen in Germany (one lower molar) and Goetzendorf in Austria (several teeth), but by far the best collection of Anapithecus comes from the R.II locality at Rudabanya in Hungary (Begun, 1989, 2002). While pliopithecoids occur with apes at a number of localities (Sukselainen et al., 2015), the only site where sympatry can be demonstrated taphonomically is Rudabanya, where the stem hominine Rudapithecus is found in the same sedimentological layer, elevations and $1 \times 1 \mathrm{~m}^{2}$ excavation units as Anapithecus (Kordos and Begun, 2001). Anapithecus is the largest-known pliopithecoid, with an estimated body mass of between about 8 and $15 \mathrm{~kg}$ (Begun, 2002; Nargolwalla et al., 2005; Begun, unpublished data). The depositional environment of the R.II locality at Rudabanya preserves the remains of a late Miocene swamp in an overall mildly seasonal forested setting (Kordos and Begun, 2001, 2002; Eronen and Rook, 2004; Eastham et al., 2016).

Nargolwalla et al. (2005) have previously depicted dental development in Anapithecus as fast in comparison to hominoids, with extreme overlap in molar development due to early initiation of sequentially erupting molar teeth. T.D. Smith et al. (2015) suggested that rates of mineralization of postcanine teeth may be more rapid in folivores compared with frugivores. Godfrey et al. (2005) have, however, noted that lemurs do not seem to reliably follow this rule. Old World monkeys are reported to lack any significant degree of molar overlap (Nargolwalla et al., 2005). Among anthropoids, growth rates (including dental development) correlate negatively with body mass: larger species have slower development and a relatively early eruption of the replacement teeth (incisors and premolars; Schwartz et al., 2007). In contrast, on the one hand, indriids show an accelerated dental development but sequences of eruption/emergence that are similar to those of hominoids. On the other hand, lemurids are characterized by a relatively slow dental eruption, whereas this sequence of eruption/emergence would be indicative of a fast process of eruption (molars erupt before premolars; Schwartz et al., 2007). Furthermore, in lemurs, there is only a poor correlation between body mass and the pace of dental development (Schwartz et al., 2007). Given the relatively large body mass estimate of Anapithecus, of about $15 \mathrm{~kg}$ (Begun, 2002; Nargolwalla et al., 2005; Begun et al., unpublished data), the conclusion of rapid dental development evidenced by closely stacked molar development seems unusual and has no known equivalent among extant catarrhines.

Multi-scale propagation phase contrast micro-computed tomography now allows a non-destructive visualization of the growth increments in dental tissues. In the present study, we employed this non-destructive imaging technique to better characterize dental development in the holotype of A. hernyaki, RUD 9, a juvenile specimen, housed in the collections of the Natural History Museum of Hungary. In addition to determining the age at death of the individual, we aimed to gather information about the dental developmental variables (e.g., longperiod striae periodicity, cuspal daily secretion rates) that had been previously estimated (Nargolwalla et al., 2005) and to describe the pattern of tooth cusp initiation and calculate enamel crown formation times. 


\section{Materials and methods}

\subsection{Sample and synchrotron micro-CT imaging}

The holotype of $A$. hernyaki, RUD 9, comprises a mandibular mixed dentition with both isolated teeth and teeth in situ (Kretzoi, 1975; Kordos and Begun, 2001; Nargolwalla et al., 2005). These include the $\mathrm{RM}_{1}$ to $\mathrm{RM}_{3}$ (all isolated), the $\mathrm{LC}_{1}$ (isolated) to $\mathrm{LM}_{2}$, as well as both left mandibular deciduous premolars. The roots of the $\mathrm{LdP}_{3}$ and the $\mathrm{LdP}_{4}$ are preserved in situ in a mandibular fragment, together with the germ of the $\mathrm{LP}_{3}$ still in its crypt beneath the $\mathrm{dP}_{3}$; the isolated germ of $\mathrm{LP}_{4}$ is also preserved. The $\mathrm{LM}_{1}$ and $\mathrm{LM}_{2}$ are both in situ in a small part of the mandible that fits together with the fragment containing the deciduous premolars.

RUD 9 was scanned at the ID 19 beamline at the European Synchrotron (ESRF, Grenoble, France). A first acquisition at $12.61 \mu \mathrm{m}$ provided an overview of the whole specimen for a morphological description (Fig. 1, Supplementary Online Material [SOM] Fig. S1). A second set of acquisitions was performed at $3.42 \mu \mathrm{m}$ to image the dental incremental growth lines in each individual tooth. Finally, the metaconid of the $\mathrm{RM}_{3}$ was subjected to two high resolution scans at $0.638 \mu \mathrm{m}$ to image the cross-striations and laminations and determine the long-period line periodicity of the individual: the first scan was acquired at the cusp tip, and the second in the cervical area of the lateral enamel. The details of the scanning parameters are provided in SOM Table S1. Virtual 2D (two-dimensional) sections were generated from the $3.42 \mu \mathrm{m}$ scans in full resolution (no binning), as well as 3D (three-dimensional) models (from the semi-automatic segmentation of the dental tissues) in VGStudio MAX2.2. The rendering techniques used here have been previously described in Le Cabec et al. (2015). All calculations of rate and measurements of length are rounded to one decimal place in the main text.

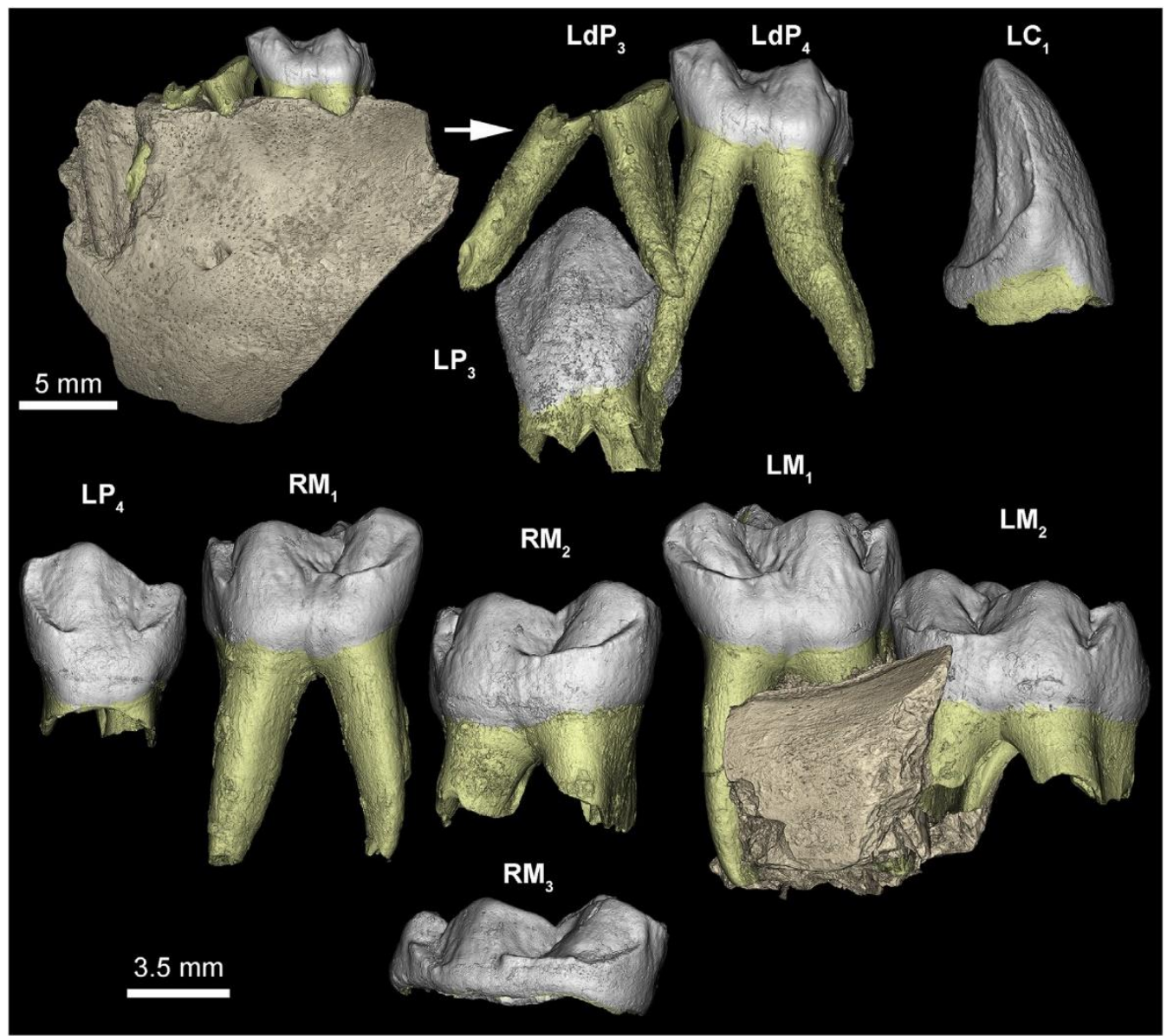

Figure 1. Three-dimensional overview of the RUD 9 dental material. Due to the black coloration of the original specimen caused by taphonomic alterations, the occlusal relief is difficult to see on the original or in photographs. Therefore, enamel and dentine were separately segmented and rendered in 3D (See SOM Fig. S1 for more details). 


\subsection{Developmental analysis}

\subsubsection{Developmental morphology}

Each tooth was described from virtual 2D sections optimized for visualizing crown and root formation, following the method described in Smith et al. (2010a). For crown development, each virtual section passed through the dentine horns of a tooth (for multi-cusped teeth, the tip of one dentine horn was set as the center of rotation of the tooth) and the pulp horns beneath. This ensured that the lowest point on the enamel cervical margin was also included in the plane of section. Similarly, for imaging root development, the plane of section passed through the pulp horns (for multi-cusped teeth, one tip of the pulp chamber was set as the center of rotation of the tooth), and included the maximum length of root possible.

\subsubsection{Determining cuspal daily secretion rates and periodicity}

Both enamel cuspal daily secretion rate (CuDSR) and long-period Retzius line periodicity were obtained from the $0.638 \mu \mathrm{m}$ scan of the $\mathrm{RM}_{3}$ metaconid. Despite the clarity of the daily laminations and/or cross-striations within the cuspal enamel, these could not be counted continuously through the whole cuspal enamel thickness because of the strong enamel decussation present. Instead, and to determine the CuDSR, the total cuspal thickness was divided into six equal zones and 10 sets of local measurements were taken across five crossstriations within each zone. Although potentially small differences may exist between tooth types, the average value obtained from the $\mathrm{RM}_{3}$ metaconid was the only one that was possible and so was used throughout this study for calculating the cuspal formation time of all teeth (see next section). Periodicity was determined from counts and measurements of daily enamel increments made between long period Retzius lines. Periodicity is usually determined by counting cross-striations between several pairs of Retzius lines reaching the outer enamel surface (OES). In this individual, daily laminations in the outer enamel were used where crossstriations could not be identified and assumed to be equivalent to daily cross-striations.

\subsubsection{Dentine daily secretion and extension rates}

Dentine daily secretion rates (DDSR) and root extension rates (DRER) in $\mu \mathrm{m} /$ day were calculated for as many tooth loci as possible. Dentine daily secretion rates were calculated by measuring a distance along the dentine tubules and then dividing it by the corresponding enamel formation time (SOM Fig. S2 and drawing in SOM Table S2). First, homologous stress lines in the dentine of the $\mathrm{P}_{4}$ and $\mathrm{M}_{2}$ were matched in both teeth. Then the same stress lines were identified in the dentine of the $\mathrm{LC}_{1}$ and matched with enamel developing at the same time to establish a formation time. Dentine daily secretion rates at the developing root apex for both $\mathrm{LP}_{4}$ and $\mathrm{RM}_{2}$ (Table 1) were both estimated in this way. Daily root extension rates were calculated by dividing the total root formation time (RFT) by the total root length (measured between the most cervical point of enamel and the most distal outer aspect of the root apex of a $2 \mathrm{D}$ virtual section). In the canine, the small portion of root formed on the disto-lingual aspect of the tooth was matched with the corresponding enamel on the mesial side, using stress lines visible in both areas. Retzius lines counted in the enamel were then used to calculate the corresponding root formation time and canine DRER (Table 1). Local DRERs were calculated in the $\mathrm{LP}_{4}$ and $\mathrm{RM}_{2}$, by using stress lines identified in the dentine of the root apex (SOM Fig. S2 and drawing in SOM Table S2). Daily root extension rate calculations for $\mathrm{LP}_{4}, \mathrm{RM}_{1}$ and $\mathrm{RM}_{2}$ were only possible across the whole root length and were calculated by dividing the overall root length by the total root formation time.

\subsubsection{Initiation times, and crown and root formation times}

In teeth that initiate before birth, the neonatal line is usually visible in the cuspal enamel and so enables the thickness of enamel formed prenatally to be measured. This thickness can 
then be divided by the CuDSR to yield the prenatal formation time, and thus the initiation time of the cusp. Regarding teeth initiating postnatally, the initiation time may be back-calculated from the age at death. If they are known, crown and root formation times can be subtracted from age at death to yield the time of initiation. This method of back-calculation can also be used to provide other missing information such as crown formation time (CFT) (or any of its components: cuspal or lateral enamel formation times) or root formation time. Stress lines in this specimen that could be matched in $2 \mathrm{D}$ and $3 \mathrm{D}$ also contributed to cross-checking tooth initiation times between tooth types $\left(\mathrm{P}_{4}\right.$ and $\left.\mathrm{M}_{2}\right)$.

Calculating CFT involves summing cuspal and lateral enamel formation times. Since Retzius lines are often difficult to identify in the cuspal area, cuspal formation time was calculated by multiplying the cuspal thickness (measured from the dentine horn to the location of the first perikymata) by the CuDSR. For the $\mathrm{LC}_{1}, \mathrm{LP}_{4}$ and $\mathrm{RM}_{3}$ the formation time for lateral enamel was based on counts of Retzius lines made on 2D virtual sections (where variation in slice thickness and orientation often improved the visibility of the incremental growth lines; see Le Cabec et al., 2015 for details). However, for $\mathrm{LP}_{3}, \mathrm{LP}_{4}$ and $\mathrm{RM}_{2}$, perikymata counts, made on high quality 3D models, multiplied by the enamel long-period line periodicity were used. Whenever possible (e.g., $\mathrm{LP}_{4}$ lateral enamel formation time), we checked the consistency of our results by counting both Retzius lines and perikymata. For most of the teeth, the method first described by Dean (2012), and subsequently refined in Dean and Cole (2013) was used and is briefly described here as used in Anapithecus teeth. From the dentine horn, at a point on the enamel-dentine junction (EDJ), a line was drawn along the path of enamel prisms to a second point $100 \mu \mathrm{m}$ into enamel formation. From this second point, an accentuated growth marking (stria of Retzius) was identified running obliquely back to the EDJ within enamel. This stria was then tracked back to intersect the EDJ further along the crown at an end point further along the EDJ. The distance along the EDJ between the start- point at the dentine horn and the end-point represents the length of EDJ formed in the same time it takes to form a $100-\mu \mathrm{m}$ thickness of enamel. The length of EDJ formed in this time represents the enamel extension rate and can be expressed in $\mu \mathrm{m} /$ day. This procedure was repeated from the cusp tip to the enamel cervix and the data for enamel formation time were cumulated. Since both perikymata and Retzius lines were visible and easily made use of most of the time, this technique was used only to verify the reliability of the counts (see SOM Table S2).

Root formation time (RFT) was calculated using one of four different methods (according to their feasibility). First, root length was measured on a slice optimized for visualizing maximum root development (as described for SOM Fig. S2), and the length divided by the DRER. Second, in some cases matching stress events across teeth between the dentine and/or the enamel of 2D sections and 3D models (EDJ, OES, or root surface) enabled a direct calculation of RFT (see Results section for $\mathrm{LP}_{4}$ and $\mathrm{RM}_{2}$ ). In this technique, previously described in Le Cabec et al. (2015), 3D images of the dentine cap and enamel surface, each containing matching stress lines, were perfectly scaled side by side with the 2D image of the longitudinal slice through the dentine horn (see Fig. 9 in Le Cabec et al., 2015). A horizontal line drawn across all three images was then passed through a matching stress line in the dentine at the EDJ (on the 2D section) and its homologous stress marking on the dentine cap surface. This point could then be tracked from the EDJ along a matching enamel stria to the corresponding perikymata on the enamel surface (see the red lines where the 2D section was recorded on the OES and dentine surface on Fig. 9 in Le Cabec et al., 2015). Figure 2B illustrates how this approach was applied on RUD 9 to estimate RFT. Third, when there was no incremental record of root formation at all but when other data for CFT, tooth initiation time and age at death were known, RFT was back-calculated from those data. Fourth, the method described by Dean and Cole (2013) and briefly described above was applied (see drawing in SOM Table S2). 
Table 1

Daily root extension rates (DRER) and dentine secretion (DDSR) rates in the permanent dentition of RUD 9.

\begin{tabular}{|c|c|c|c|c|c|}
\hline Tooth & Root length $[\mathrm{mm}]$ & DRER $[\mathrm{mm} / \mathrm{d}]$ & Method for DRER & $\operatorname{DDSR}[\mathrm{mm} / \mathrm{d}]$ & Method for DDSR \\
\hline Local $\mathrm{LC}_{1}$ (cervix) & 1300 & 12.74 & 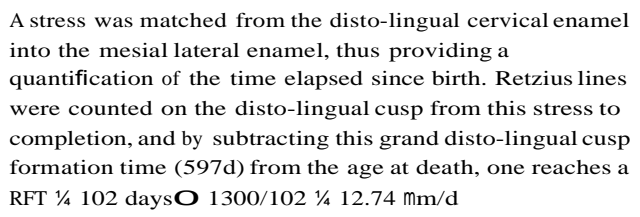 & e & e \\
\hline Overall $\mathrm{LP}_{4} \mathrm{D}$ & 2274 & 11.44 & From the RFT 1/4 147 days $O 2274 / 1471 / 411.44 \mathrm{~mm} / \mathrm{d}$ & e & e \\
\hline Local $\mathrm{LP}_{4}$ (developing apex) & 877 & 10.83 & $\begin{array}{l}\text { From root length measured from death to the double stress, } \\
\text { distance representing } 81 \text { days. }\end{array}$ & 4.35 & $\begin{array}{l}\text { Was calculated from the double stress we use as a reference } \\
\text { to death (i.e., developing front): } 352.15 \mathrm{~mm} \text { (distance from } \\
\text { death to the stress following the direction of the dentine } \\
\text { tubules)/81days. The corresponding time ( } 81 \text { days) was } \\
\text { securely measured by matching the stress observed in the } \\
\mathrm{LP}_{4} \text { dentine on a } 2 \mathrm{D} \text { virtual section onto the } 2 \mathrm{D} \text { section of } \\
\text { the } \mathrm{LC}_{1} \text { for which we have precise Retzius line counts to } \\
\text { death (See SOM Fig. S2). It follows that an interval of } 100 \mathrm{~mm} \\
\text { (following Dean, 1998; Dean and Vesey, 2008) corresponds } \\
\text { to } 23 \text { days. }\end{array}$ \\
\hline Overall $\mathrm{RM}_{1}$-hypoconulid & 7753 & 17.32 & $\begin{array}{l}\text { RFT 1/4 age at death-postnatal CFT } 1 / 4699 \mathrm{e} 251.51 / 4447.5 \\
\text { days. } 7753 / 447.51 / 417.32 \mathrm{~mm} / \mathrm{d}\end{array}$ & e & e \\
\hline Overall $\mathrm{RM}_{2}$-protoconid & 2933 & 9.25 & $\mathrm{RFT}^{1 / 4} 317$ days $\mathrm{O} 2933 / 317^{1 / 4} 9.25 \mathrm{~mm} / \mathrm{d}$ & e & e \\
\hline Local $\mathrm{RM}_{2}$ (developing apex) & 812 & 10.02 & $\begin{array}{l}\text { From root length measured from death to the double stress, } \\
\text { distance representing } 81 \text { days. Consistent with LP } 4 \text { 's local } \\
\text { DRER. }\end{array}$ & 4.34 & 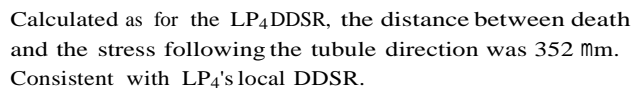 \\
\hline
\end{tabular}




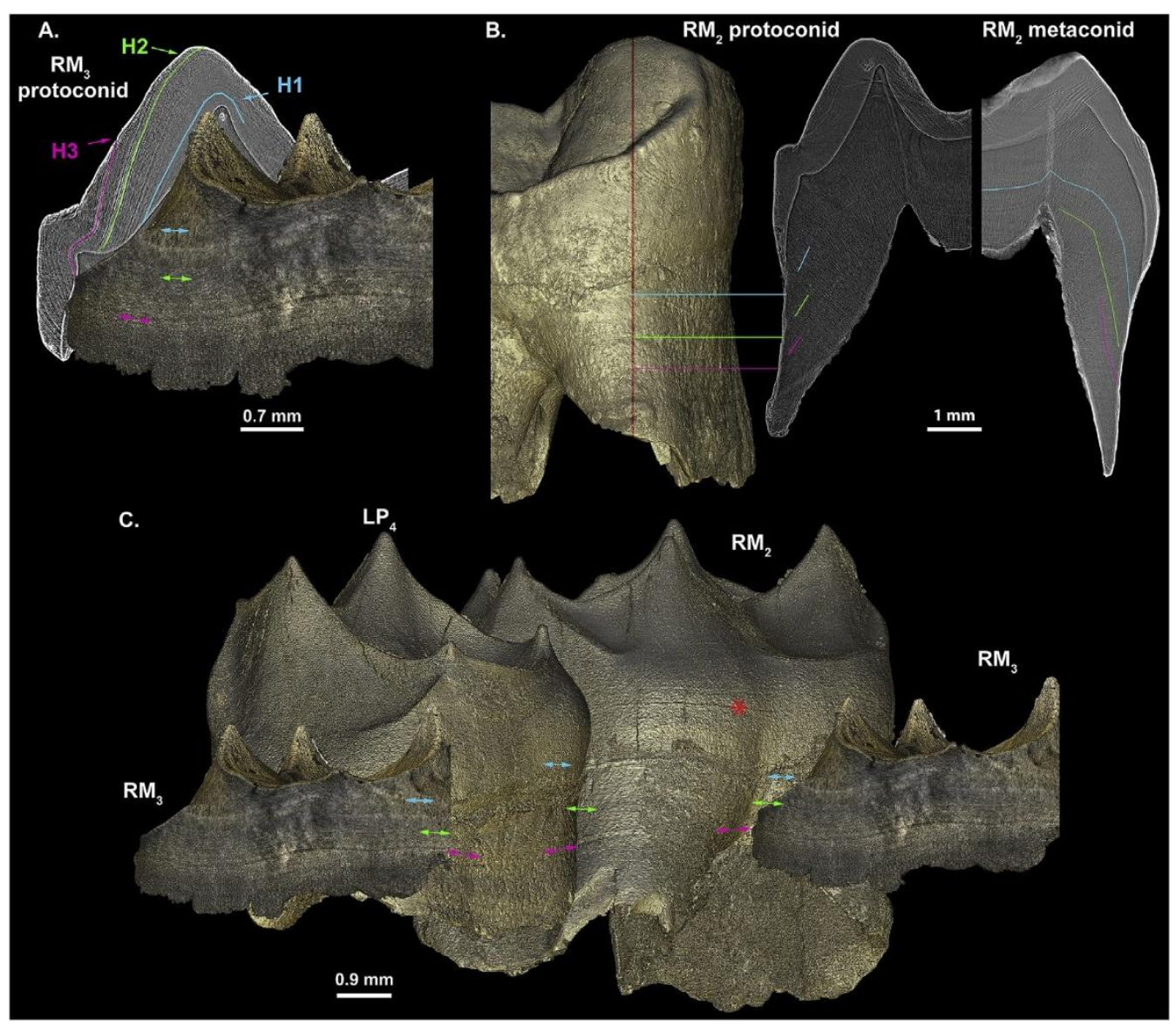

Figure 2. Stress matching between the EDJ, root surface and 2D internal structure of LP4, RM2 and RM3. The matching of stress markers (indicated by colored lines and arrows) on the EDJ and on the 2D internal structure (A for RM3), on the root surface and the 2D section (B for RM2), and between EDJ and root surface (C for RM3, LP4 and RM2) allows cross- checking of the calculations underlying the developmental chart. This also allows visualization of how much tooth was formed across the dentition, and how fast the different tooth types may have grown. This is based on three stress events which are visible as stress lines in the RM3 enamel, in the RM2 dentine and onto the 3D models of the RM3 EDJ, the LP4 and LM2 root surface and the LP4 enamel cap. "H1" (in turquoise) is the earlier stress occurring in the RM3 enamel at $\sim 105$ RL from death, i.e., at the $~ 384$ th day and thus at 1.1 years of RUD 9's life. "H1" corresponds to the completion of the RM2 protoconid. "H2" (in green) is a stress corresponding to the end of the formation of the RM3 cuspal enamel, and occurring at 63 Retzius lines from death ( $~ 510$ th day), i.e., at 1.4 years of life of RUD 9. "H3" (in pink) corresponds to the completion of the buccal cusp of the LP4, at 49 pk from death, i.e., 552nd day or at 1.5 years of life of RUD 9. The red asterisk on the EDJ of the RM2 (C) figures another stress (no precise time determined) mentioned in the morphological description of the teeth. (For interpretation of the references to color in this figure legend, the reader is referred to the web version of this article.)

\subsubsection{Age at death}

Ideally age at death is best calculated from a single tooth that registered both birth (neonatal line) and death. The sum of the postnatal cuspal enamel and the lateral enamel formation times and any additional root formation time equals the age at death of RUD 9. In the case of RUD 9, based on preservation, the canine was determined to be the best tooth for this calculation, but the enamel formed last was counted in the third molar (as the cervix of the canine appears to be slightly damaged) and so both teeth were used in the final calculation.

\section{Results}

\subsection{Tooth formation stages}

The developmental stage of each tooth is illustrated in 3D in SOM Fig. S1, and in 2D in SOM Fig. S3. Both deciduous premolars and the $\mathrm{LP}_{3}$ are preserved in their anatomical position in one fragment of the jaw, while the $\mathrm{LM}_{1}$ and $\mathrm{LM}_{2}$ are in situ in a second fragment of the jaw. 


\subsection{1. $\mathrm{LdP}_{3}$}

The crown and the cervical part of the mesial and distal roots are broken off. Only the roots are preserved in situ. In cross section, the mesial root is triangular in shape while the distal root is figure-of-eight shaped. At about half of the root length, both roots divide into two root canals, with the buccal root being broader. The distal root, the tip of which is broken off, has caused a localized resorption area on the LdP4 mesial root. This is most likely due to space competition in the lingual aspect of the jaw, as there is no indication of pathology. None of the LdP3 roots seems to be affected by any significant root resorption, despite the presence of the well-developed LP3 germ beneath them. A significant amount of cementum is deposited on the LdP3 roots: sagittally, a $\sim 175 \mu \mathrm{m}$-thick layer on the distal aspect of the mesial root, and a $\sim 240$ $\mu \mathrm{m}$-thick layer on the mesial aspect of the distal root.

\subsection{2. $\mathrm{LdP}_{4}$}

All cusps are worn down further than a third of the dentine horn heights. Both the mesial and the distal roots change from C-shaped cross section cervically into a figure-of-eight shaped cross section apically, where the root canals divide into two major branches with accessory canals spreading out laterally. On its lateral aspect the mesial root is affected by a localized resorption, presumably due to the crowding of the $\mathrm{LdP}_{3}$, and again apically due to contact with the $\mathrm{LP}_{3}$ germ positioned in its crypt beneath. The amount of root resorption, however, is negligible with respect to the stage of development of the $\mathrm{LP}_{4}$ germ underneath. There is, however, a considerable accumulation of cementum over the whole length of the $\mathrm{LdP}_{3}$ and $\mathrm{LdP}_{4}$ roots. The mesio-lingual component of the mesial root of the $\mathrm{LdP}_{4}$ has a $\sim 400 \mu \mathrm{m}$-thick layer of cementum in the apical fifth on its distal aspect, and a $\sim 575 \mu \mathrm{m}$ layer of cementum at the root apex. The cementum deposition follows the same pattern in the distal root although it is somewhat more bulbous in some places. For both deciduous premolars, several accessory canals of variable diameter $(\sim 150 \mu \mathrm{m}$ maximum) branch in a complex ramification involving the apical root pulp canal, although without reaching the root surface.

\subsection{3. $L C_{1}$}

The crown of this unerupted tooth is complete or nearly so, although slightly broken at the cervix on the mesial side. On the disto-lingual aspect of the tooth, the crown is complete and 1.3 $\mathrm{mm}$ of root had already formed. The crown is $8807 \mu \mathrm{m}$ high in the developmental section from the dentine horn to the most cervical point of enamel (mesial side).

\subsection{4. $L P_{3}$ and $L P_{4}$}

Both premolars were still in their crypts (only $\mathrm{LP}_{3}$ is preserved in situ), and both are crown complete. Less than a third of the $\mathrm{LP}_{3}$ root is formed overall (based on comparison with another Anapithecus specimen with complete and undamaged roots, RUD 222, in which the P3 root is $10.5 \mathrm{~mm}$ long), the lingual aspect being $2138 \mu \mathrm{m}$ long. The $\mathrm{LP}_{4}$ root is $2274 \mu \mathrm{m}$ long on its mesiolingual aspect, with a linear root hypoplasia at $592 \mu \mathrm{m}$ from the cervix that corresponds to crown completion on the buccal side.

\subsection{5. $R M_{1}$}

At the time of RUD 9's death, this tooth had been in functional occlusion for long enough to produce wear facets on all cusps. Although their roots have not yet achieved apical closure, both M1s already show a noticeable narrow layer of cementum on their apical fifth (approximate maximum thickness measured on 2D sections: $125 \mu \mathrm{m}$ on the mesial root, and $\sim 205 \mu \mathrm{m}$ on the mesial aspect of the distal root). 


\subsection{6. $R M_{2}$}

Although the roots are almost half formed (estimated from comparisons with the fully formed $\mathrm{M}_{2}$ roots of RUD 61, 112 and 222 that are overall $9.9 \mathrm{~mm} \pm 0.5 \mathrm{~mm}$ long), and so similar to the $\mathrm{LP}_{4}$, the $\mathrm{M}_{2} \mathrm{~S}$ are advanced in their stage of eruption when compared to the $\mathrm{LP}_{4}$. The level of the cusp tips of the $\mathrm{LM}_{2}$ is half way up the $\mathrm{M}_{1}$ crown (Fig. 1). Two strong linear hypoplastic markings are visible on the surface of all roots, while another hypoplastic marker-line can be seen on the surface at about the cervical quarter of the EDJ (see the red asterisk on Fig. 2).

\subsection{7. $R M_{3}$}

About three quarters of the unerupted $\mathrm{RM}_{3}$ crown is mineralized. The enamel has recorded several stresses also visible as hypoplastic lines on the dentine surface.

\subsection{Developmental histology}

\subsubsection{Periodicity and daily secretion rate in cuspal enamel}

In the metaconid of the $\mathrm{RM}_{3}$, the enamel long-period line periodicity was observed to be three days (Fig. 3). The average CuDSR is $4.4 \mu \mathrm{m} / \mathrm{d}$ (Table 2).

\subsubsection{Daily root extension rates (DRER) and dentine daily secretion rates (DDSR)}

Results are reported in detail in Table 1 and SOM Table S2. A daily root extension rate of $12.7 \mu \mathrm{m} / \mathrm{d}$ was calculated from the small portion of root preserved on the $\mathrm{LC}_{1}$ (disto-lingual side).

Stress events identified in the $\mathrm{RM}_{3}, \mathrm{RM}_{2}$ and $\mathrm{LP}_{4}$ were employed to calculate DRER and DDSR in the $\mathrm{P}_{4}$ and $\mathrm{M}_{2}$. Three of the most accentuated stress lines observed in the $\mathrm{RM}_{3}$ enamel were indeed also visible as linear hypoplastic markings on the $3 \mathrm{D}$ models of the $\mathrm{P}_{4}$ and $\mathrm{M}_{2}$ EDJ and root surface (Fig. 2). The earlier stress (i.e., the closest accentuated line to the dentine horn tip of the $\mathrm{RM}_{3}$ on Fig. 2A) corresponds to the protoconid completion in the $\mathrm{RM}_{2}$ and is represented in blue in Figures 2 and 4 . This blue stress event occurred at the $\sim 384^{\text {th }}$ day of the life of RUD 9. It should be noted that determining the time of occurrence of a stress marking cannot be done with precision to a single day since rounding of the various calculations involved inevitably leads to variation of a few days. The second stress event, represented by a green line (Figs. 2 and 4), coincides with the end of the formation of the cuspal enamel in the $\mathrm{RM}_{3}$ and occurred at the $\sim 510^{\text {th }}$ day of life of RUD 9. The last stress event of interest is figured as a pink line (Figs. 2 and 4), and took place at the $\sim 552^{\text {nd }}$ day of RUD 9's life. This stress event, that matches across teeth, provided a means to calculate overall DRER. The LP 4 DRER on the buccal side is $11.4 \mu \mathrm{m} / \mathrm{d}$. This value has been supported by another measurement yielding 12.0 $\mu \mathrm{m} / \mathrm{d}$, using the method described in Dean and Cole (2013): see Methods section for explanation and SOM Table S2. Another stress line corresponding to the completion of the protoconid in the $\mathrm{RM}_{2}$ allowed calculation of a DRER of $9.3 \mu \mathrm{m} / \mathrm{d}$. Finally a DRER of $17.3 \mu \mathrm{m} / \mathrm{d}$ was calculated from the disto-buccal root of the $\mathrm{RM}_{1}$.

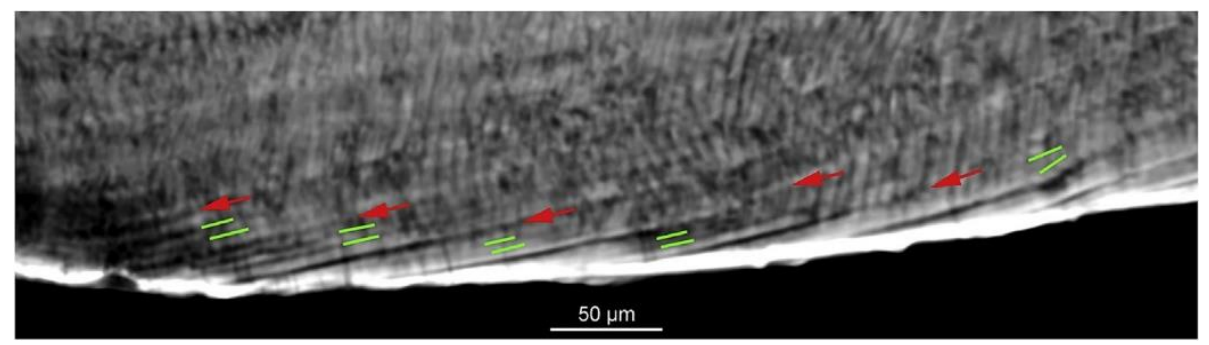

Figure 3. Long-period line periodicity in the metaconid of the RUD $9 \mathrm{RM}_{3}$. Sets of three laminations (delineated by green lines) are visible in between Retzius lines (red arrows) on the cuspal $0.638 \mu \mathrm{m}$ scan, yielding an enamel long-period line periodicity of 3 days. (For interpretation of the references to color in this figure legend, the reader is referred to the web version of this article.)

Another set of stress events, involving a double stress marking, was identified in the $\mathrm{LP}_{4}$, 
the $\mathrm{RM}_{2}$ and the $\mathrm{LC}_{1}$ dentine. From matching the stress pattern between the dentine of the $\mathrm{LP}_{4}$ and the $\mathrm{LC}_{1}$ enamel, the latest accentuated line of this double stress event, i.e., the closest to death, was shown to have formed at 81 days before death (SOM Fig. S2). Measuring the distance between this stress event (i.e., the stress line of this pair closest to death which was easily recognizable in the dentine of $\mathrm{LP}_{4}$ and $\mathrm{RM}_{2}$ ) and death (i.e., the last deposited incremental growth layer, in each tooth) along the dentine tubules provided a local DDSR of $4.4 \mu \mathrm{m} / \mathrm{d}$ (measured from the distance at the blue double-arrow in SOM Fig. S2) and a local DRER of 10.8 $\mu \mathrm{m} / \mathrm{d}$ for the $\mathrm{LP}_{4}$ (green double-arrow in SOM Fig. S2), and a local DDSR $=4.3 \mu \mathrm{m} / \mathrm{d}$ and a local DRER $=10.0 \mu \mathrm{m} / \mathrm{d}$ in the RM2. About two dozen Retzius lines were clearly visible at the cervix of the protoconid of the RM2. In this region, a distance of $100 \mu \mathrm{m}$ along the enamel prisms corresponds to eight Retzius lines, or 24 days (see the description in the Methods section and in SOM Table S2). The corresponding EDJ length is $145 \mu \mathrm{m}$, yielding a cervical EDJ extension rate of $6.0 \mu \mathrm{m} / \mathrm{d}$. Likewise, $100 \mu \mathrm{m}$ measured along the dentine tubules just below the cervix corresponds to a root length of $323 \mu \mathrm{m}$ but to a faster local DRER of $13.5 \mu \mathrm{m} / \mathrm{d}$.

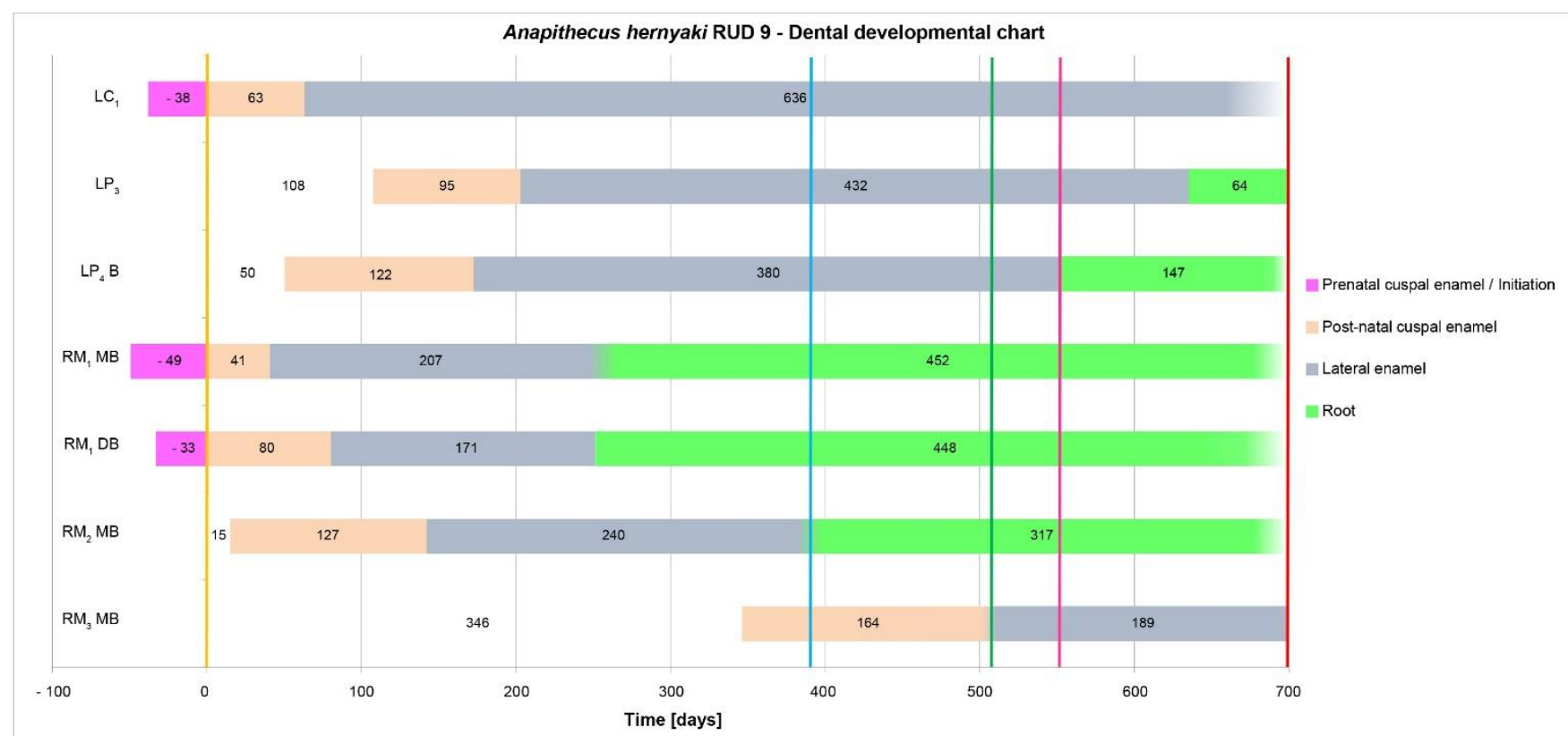

Figure 4. Developmental chart of the RUD 9 permanent dentition. This chart provides an overview of the sequence of dental development of RUD 9. Cuspal enamel, lateral enamel and root formation are indicated using different colors, and any uncertainty in the timing of these events is represented by using color-fading at the transition between them. Birth and death are indicated as well as three additional stress events that were visible as stress lines in dentine and enamel on 2D virtual sections and as linear enamel hypoplasia in 3D. These stress events were important throughout for checking the congruence of matching developmental stages of all the teeth. Initiation, cuspal and lateral enamel formation times as well as root formation times are reported for each tooth investigated. The calculation of temporal spacing between noticeable stress markings, such as birth, three hypoplastic lines and death, locks each tooth into the chart chronologically. (For interpretation of the references to color in this figure legend, the reader is referred to the web version of this article.)

Table 2. Daily secretion rates measured in the metaconid of RUD9's RM 3 , using a $0.638 \mu$ m synchrotron scan'.

\begin{tabular}{llccc}
\hline Cuspal third & Cuspal zone & Mean & SD & Range \\
\hline Inner & Inner & 3.98 & 0.42 & $3.39-4.64$ \\
& Outer & 3.86 & 0.70 & $3.06-5.13$ \\
\multirow{3}{*}{ Middle } & Inner & 4.70 & 0.74 & $3.45-5.92$ \\
& Outer & 4.51 & 0.72 & $3.75-6.16$ \\
\multirow{2}{*}{ Outer } & Inner & 4.60 & 0.46 & $3.99-5.33$ \\
& Outer & 4.63 & 0.42 & $4.06-5.36$ \\
\hline Total average & & $\mathbf{4 . 3 8}$ & & \\
\hline
\end{tabular}

a Measurements (all expressed in $\mu \mathrm{m} / \mathrm{d}$ ) were taken from 10 different locations per cuspal zone, each time across five cross-striations. The mean, standard deviation (SD) and range for each zone are reported here. 
Figure 5 illustrates the cumulative increase in tooth height along the EDJ and CDJ (cemento-enamel junction) plotted against tooth formation time for the $\mathrm{P}_{4}$ and $\mathrm{M}_{2}$ in RUD 9. It demonstrates the earlier initiation time of the $\mathrm{M}_{2}$ than the $\mathrm{P}_{4}$ and also how closely these two teeth track each other in height gained over time. Early root growth rates in each tooth type are notably similar. Figure 6 shows the same data for $M_{2}$ in a comparative context. Few truly appropriate data are available for comparison, but the crowns and roots of Gorilla $\mathrm{M}_{2} \mathrm{~s}$ achieve greater heights than those of Pan by growing at faster rates. Hispanopithecus (Dean and Kelley, 2012) resembles Pan in growing a low squat crown more slowly, while Victoriapithecus (Dean and Leakey, 2004), Oreopithecus (Zanolli et al., 2016) and Anapithecus show faster rates of crown and root extension than Pan $\mathrm{M}_{2} \mathrm{~s}$ and more closely resemble those of Gorilla.

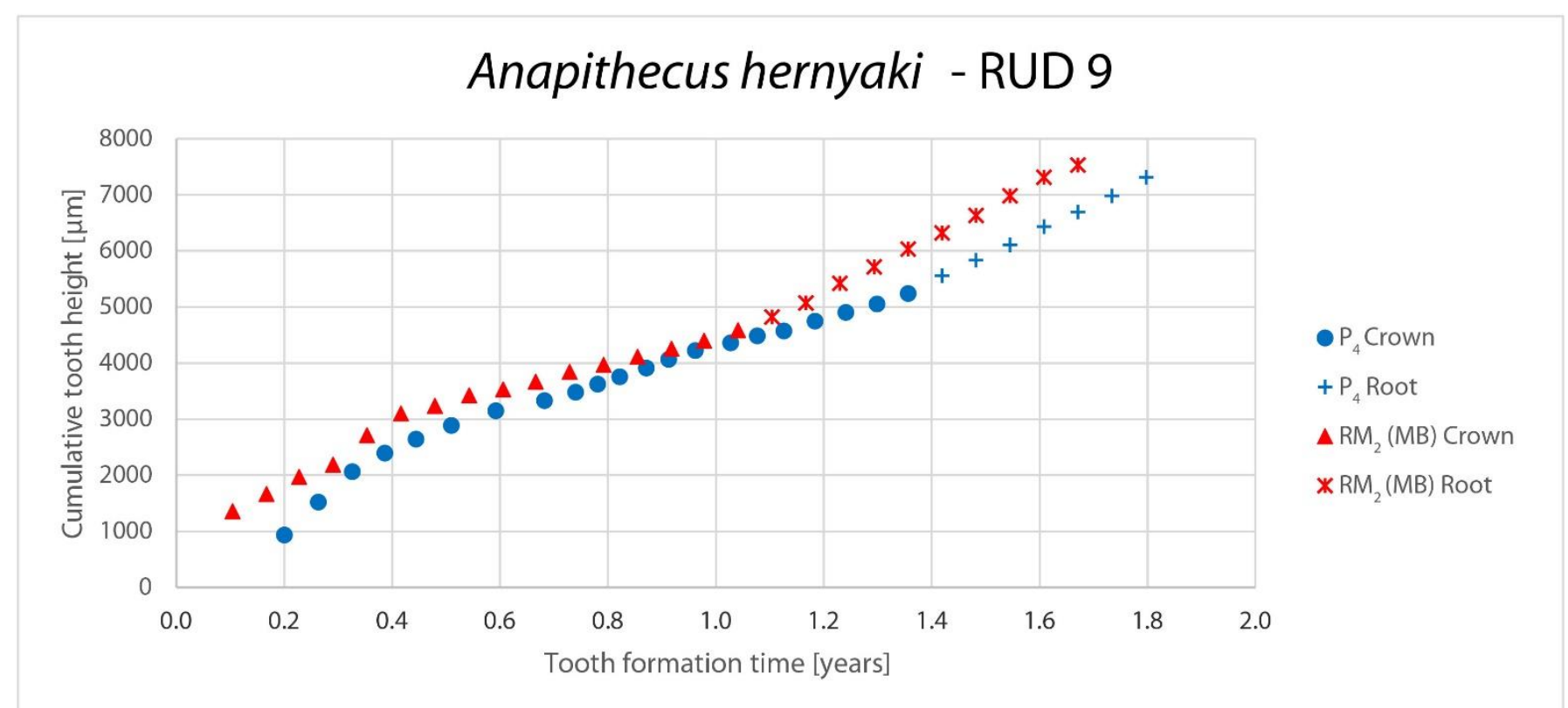

Figure 5. Plot of tooth height along the EDJ and continuing on along the cemento-dentine junction against tooth formation time for the $\mathrm{LP}_{4}$ (B cusp) and $\mathrm{RM}_{2}$ (protoconid) of RUD 9.

\subsubsection{Crown (CFT) and root formation (RFT) times (Table 3 and SOM Table S2)}

Neither of the deciduous premolars showed incremental growth lines or stress lines that could be reliably identified, in either the enamel or in the dentine (SOM Fig. S3). Cuspal formation times were calculated from measurements of cuspal thickness using the average CuDSR of $4.4 \mu \mathrm{m} / \mathrm{d}$. Lateral enamel formation times in the $\mathrm{LC}_{1}, \mathrm{LP}_{4}$ and $\mathrm{RM}_{3}$ were calculated from counts of Retzius lines. In the LC1, the enamel and dentine growth lines meet the EDJ with a similar angle, suggesting comparable secretion rates. Perikymata were visible on the 3D model of the $\mathrm{LP}_{4}$ buccal aspect, providing confirmation of the $2 \mathrm{D}$ count. Lateral enamel formation time was calculated from perikymata counts for the $\mathrm{RM}_{2}$ protoconid and the $\mathrm{RM}_{1}$ hypoconid. In the case of the $\mathrm{RM}_{1}$ protoconid, lateral enamel formation time was backcalculated from the age at death.

Despite the fact that no growth increments could be visualized in the $\mathrm{LP}_{3}$ virtual $2 \mathrm{D}$ sections, perikymata were visible on the 3D rendering of the OES except on the cuspal-most quarter of the OES. Even though this may be speculative, an attempt was made to calculate CFT, RFT and initiation time for this tooth. In addition to the 123 perikymata identified on the 3D model of the $\mathrm{LP}_{3}$ buccal aspect, the last cuspal-most portion of the OES was estimated to have 21 perikymata, giving a total of 144 perikymata or 432 days. The cuspal formation time was calculated to be 95 days ( $418 \mu$ m-thick cusp), leading to a total CFT of 527 days. The DRER of the $\mathrm{LP}_{4}$ was applied to calculate the RFT: $734.75 \mu \mathrm{m} / 11.4 \mu \mathrm{m} / \mathrm{d}=64$ days. 
When considering tooth growth as a whole, Figures 5 and 6 show that the CFTs of hominoid teeth vary greatly but those with absolutely taller crowns and longer roots appear to achieve this primarily by having faster extension rates in both enamel and root dentine (Zanolli et al., 2016).

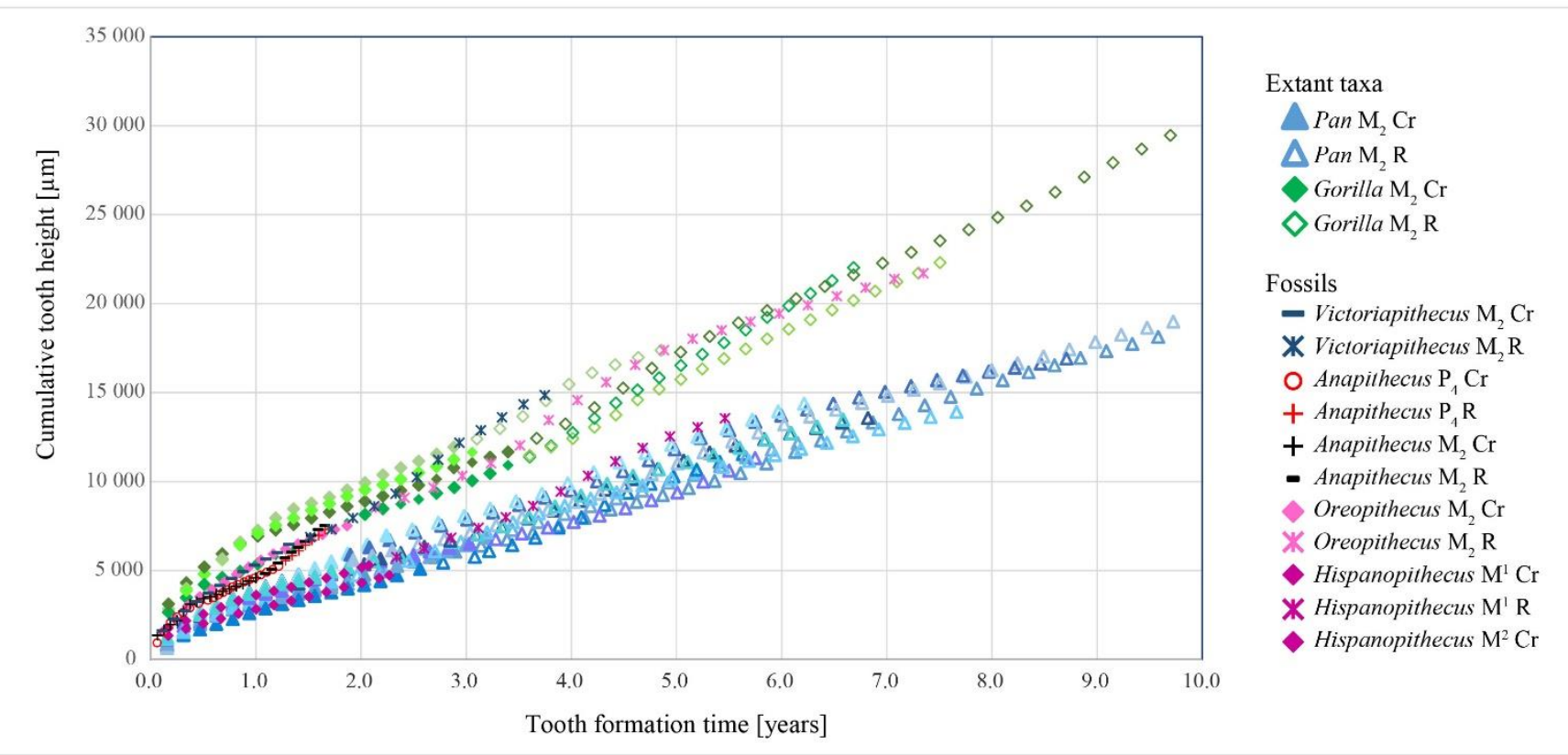

Figure 6. Plots of cumulative growth in $\mathrm{M}_{2}$ crown and root height along the EDJ and CDJ against tooth formation time (years). Data for the Anapithecus (RUD 9) $\mathrm{M}_{2}$ and $\mathrm{P}_{4}$ are compared with published data for five Gorilla $\mathrm{M}_{2} \mathrm{~S}$ and 10 Pan $\mathrm{M}_{2} \mathrm{~S}$ and with Hispanopithecus (an $\mathrm{M}^{1}$ with root: IPS-1781, and an $\mathrm{M}^{2}$ crown: IPS-1794; Dean and Kelley, 2012), Oreopithecus (an M 2 : FS\#BC-nn; Zanolli et al., 2016) and Victoriapithecus (an M2: KNM MB 19841; Dean and Leakey, 2004). The Pan and Gorilla samples are largely derived from the Elliot Smith Collection at University College London, and are described and referenced in Dean (2010) and Dean and Cole (2013).

Table 3. Histological features of the RUD 9 permanent tooth crownsa.

\begin{tabular}{|c|c|c|c|c|}
\hline & Cuspal formation time & Lateral enamel formation time & CFT & Cusp height \\
\hline $\mathrm{LC}_{1}$ & $\begin{array}{l}\text { prenatal: } 166 \mu \mathrm{m} \Leftrightarrow 38 \text { days } \\
\text { postnatal: } 277 \mu \mathrm{m} \Leftrightarrow 63 \text { days } \\
\text { total cuspal: } 443 \mu \mathrm{m} \Leftrightarrow 101 \text { days }\end{array}$ & $\begin{array}{l}200 \mathrm{RL}+12 \mathrm{RL} \text { (matching with } \mathrm{RM}_{3} \text { cervix) } \\
\Leftrightarrow 636 \text { days }\end{array}$ & 737 days & $8454 \mu \mathrm{m}$ \\
\hline $\mathrm{LP}_{3}$ (Buccal) & $417.7 \mu \mathrm{m} \Leftrightarrow 95$ days & $144 \mathrm{pk} \Leftrightarrow 432$ days & 527 days & $6044 \mu \mathrm{m}$ \\
\hline $\mathrm{LP}_{4}$ (Buccal) & $536.2 \mu \mathrm{m} \Leftrightarrow 122$ days & $125 \mathrm{pk} / 128 \mathrm{RL} \Leftrightarrow 380$ days & 502 days & $5145 \mu \mathrm{m}$ \\
\hline $\begin{array}{l}\mathrm{RM}_{1} \\
\text { (Protoconid) }\end{array}$ & $\begin{array}{l}\text { prenatal: } 215.5 \mu \mathrm{m} \Leftrightarrow 49 \text { days } \\
\text { postnatal: } 178.5 \mu \mathrm{m} \Leftrightarrow 41 \text { days } \\
\text { total cuspal: } 394 \mu \mathrm{m} \Leftrightarrow 90 \text { days }\end{array}$ & $\begin{array}{l}207 \text { days (back-calculated, see SOM Table } \\
\text { S2). }\end{array}$ & 297 days & $4354 \mu \mathrm{m}$ \\
\hline $\begin{array}{l}\mathrm{RM}_{1} \\
\text { (Hypoconulid) }\end{array}$ & $\begin{array}{l}\text { prenatal: } 144 \mu \mathrm{m} \Leftrightarrow 33 \text { days } \\
\text { postnatal: } 352 \mu \mathrm{m} \Leftrightarrow 80.5 \text { days } \\
\text { total cuspal: } 496 \mu \mathrm{m}^{*} \Leftrightarrow 113 \text { days }\end{array}$ & $57 \mathrm{RL} \Leftrightarrow 171$ days & 284 days & $4619 \mu \mathrm{m}$ \\
\hline $\begin{array}{l}\mathrm{RM}_{2} \\
\text { (Protoconid) }\end{array}$ & $556 \mu \mathrm{m} \Leftrightarrow 127$ days & $80 \mathrm{RL} \Leftrightarrow 240$ days & 367 days & $4354 \mu \mathrm{m}$ \\
\hline $\begin{array}{l}\mathrm{RM}_{3} \\
\text { (Protoconid) } \\
\text { Crown not } \\
\text { complete }\end{array}$ & $718 \mu \mathrm{m} \Leftrightarrow 164$ days & $63 \mathrm{RL} \Leftrightarrow 189$ days & 353 days & $2894 \mu \mathrm{m}$ \\
\hline $\begin{array}{l}\text { Prediction } \\
\text { crown } \\
\text { complete }\end{array}$ & & $83 \mathrm{RL} \Leftrightarrow 249$ days & 413 days & $3235 \mu \mathrm{m}$ \\
\hline
\end{tabular}

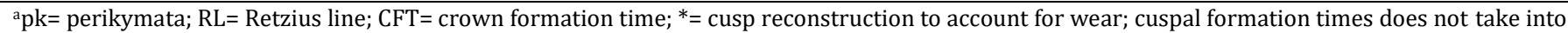
account decussation and is calculated with the average rate at $4.4 \mu \mathrm{m} / \mathrm{d}$ (See Table 1). The cusp height was measured as the projected distance between the dentine horn tip and the cervical-most point of enamel on the crown side of the cusp of interest. 


\subsubsection{Initiation times}

Both the $\mathrm{RM}_{1}$ and the $\mathrm{LC}_{1}$ show two equally spaced stress lines in their cuspal enamel (SOM Fig. S4). This temporal equidistance was confirmed by the identification of 13 Retzius lines between both stress lines, in each tooth. Although Retzius lines are difficult to visualize reliably in the cuspal enamel, it seems very unlikely that there might be a large difference in the actual number of growth layers between the two teeth. It follows that, as is commonly accepted for the permanent first molar, the stress line closest to the dentine horn in the canine is reasonably assumed to be the neonatal line (SOM Fig. S4). Since the existence of the neonatal line (NL) was demonstrated in both $\mathrm{LC}_{1}$ and $\mathrm{RM}_{1}$, the time required to form the prenatal enamel was calculated by multiplying the distance between the dentine horn tip and the NL (along the enamel prisms path) by the average CuDSR of $4.4 \mu \mathrm{m} / \mathrm{d}$. The canine was found to initiate 38 days before birth, while the $\mathrm{RM}_{1}$ mesio-buccal (MB) and the disto-buccal (DB) cusps started forming 49 and 33 days prenatally respectively (Table 4, SOM Table S2).

All the other initiation times were back-calculated by subtracting the CFT and potential RFT from the age at death (SOM Table S2). The $\mathrm{LP}_{4}$ and the $\mathrm{LM}_{2}$ were found to initiate 50 and 15 days after birth, respectively. As highlighted above, the results for the $\mathrm{LP}_{3}$ are less reliable than for the other teeth, but the $\mathrm{LP}_{3}$ initiation occurred 108 days after birth, which is more than 50 days after the $\mathrm{LP}_{4}$. Last, the $\mathrm{RM}_{3}$ protoconid initiated 346 days postnatally (Table 4).

Table 4. Developmental summary of the RUD 9 dentitiona.

\begin{tabular}{lccc}
\hline Tooth & Initiation & CFT & RFT \\
\hline $\mathrm{LC}_{1}$ & -38 & 737 & (102 for disto-lingual side) \\
$\mathrm{LP}_{3}$ & 108 & 527 & 64 \\
$\mathrm{LP}_{4}$ & 50 & 502 & 147 \\
$\mathrm{RM}_{1}(\mathrm{MB})$ & -49 & 297 & 452 \\
$\mathrm{RM}_{2}(\mathrm{MB})$ & 15 & 367 & 317 \\
$\mathrm{RM}_{3}(\mathrm{MB})$ & 346 & $353 \rightarrow 413$ & - \\
\hline
\end{tabular}

${ }^{a}$ All values are expressed in days. The predicted values for completing the dentition are in italics. MB = metaconid; CFT = crown formation time; RFT = root formation time.

\subsection{Developmental pattern}

\subsubsection{Age at death}

Because the cuspal enamel of the LC1 contains evidence of the NL (SOM Fig. S4), the postnatal crown formation time of this tooth could be used to calculate the age at death. Although the cervix is damaged on the mesial side, by matching several stress lines with the lateral enamel of the $\mathrm{RM}_{3}$ it was possible to derive the information required to estimate age at death. The $\mathrm{LC}_{1}$ postnatal cuspal enamel formed in 63 days $(277 \mu \mathrm{m} / 4.4 \mu \mathrm{m} / \mathrm{d})$ and its lateral enamel contained 200 Retzius lines (i.e., 600 days) but some enamel was lost postmortem. Lateral enamel formation in the $\mathrm{RM}_{3}$ could be matched with the $\mathrm{LC}_{1}$ and continued on for an additional 12 Retzius lines (RL). These additional $12 \mathrm{RL}$ from the $\mathrm{RM}_{3}$ bring the lateral enamel formation time of the $\mathrm{LC}_{1}$ to 3 days $\times 212 \mathrm{RL}=636$ days. This gives an age at death of $63+636=$ 699 days or 1.9 years (Fig. 4, Table 4 and SOM Table S2).

The age at death together with the initiation times, the CFT and the RFT allowed a developmental chart, Figure 4, to be constructed to visualize the sequence of initiation and crown completion of all teeth investigated up until the time of death. The three stress markings identified in the $\mathrm{RM}_{3}$ protoconid enamel and matched on the EDJ and root surfaces of the RM $\mathrm{R}_{2}$ and $\mathrm{LP}_{4}$ (blue, green and pink lines; Figs. 2 and 4) appear on the chart as vertical lines and provide a means of checking for internal consistency of all the calculations made.

\subsubsection{Projection of dental development to completion}

For comparative purposes it would be useful to attempt to predict the age by which RUD 
9 would have completed its permanent dentition. Nonetheless, since the $M_{3}$ had not quite reached crown completion, estimating its final root length and root formation time would be questionable. However, because the $\mathrm{M}_{3}$ crown is so close to completion, we can at least estimate the time remaining to complete enamel formation based on morphological evidence from other molar teeth belonging to RUD 9 and other Anapithecus specimens.

We observed that both $\mathrm{M}_{1}$ and $\mathrm{M}_{2}$ have complete crowns and that the buccal cingulum is located at $\sim 50 \%$ of the total crown height (measured from the cusp tip to the most cervical point in the MB developmental plane e as described in the Methods section and in Smith et al. (2010a) e in the virtual section). This is also the case on the MB aspect of two mandibular third molars belonging to another Anapithecus individual, RUD 98, in which the buccal cingulum was located at $50.7 \%$ of crown height for the $\mathrm{LM}_{3}$, and $53.5 \%$ for the $\mathrm{RM}_{3}$. If we assume on this basis that RUD 9's $\mathrm{RM}_{3}$ would have followed the same pattern then the additional near-vertical length of EDJ $(353 \mu \mathrm{m})$ corresponds to approximately 20 Retzius lines in the cervical enamel. This is equivalent to $\sim 60$ days to reach crown completion, giving a total CFT of 413 days.

\section{Discussion}

\subsection{Reassessment of Anapithecus dental development}

Overall, we found a pattern of rapid and precocious dental development in RUD 9, the $A$. hernyaki holotype, compared to other catarrhines, which was previously highlighted for the species by Nargolwalla et al. (2005). We estimated the age of death of RUD 9 to be 1.9 years. There were some key differences in approach between Nargolwalla et al.'s (2005) work and our study, which go some way towards explaining a number of divergent findings discussed in more detail below. First, it was the aim of Nargolwalla et al. (2005) to pool data from several individuals in order to describe and deduce the pattern and timing of dental development in Anapithecus generally, whereas in the present study our aim was to describe the timing of dental development in a single individual. Second, because Nargolwalla et al. (2005) relied on surface features revealed through microscopy and were not able to make histological sections, they made estimates of Retzius line periodicity, cuspal thickness and daily secretion rates, crown initiation times, and root extension rates. In this study, which was also non-destructive, synchrotron micro-tomography allowed us to reveal much of the internal tooth structure, and so enabled informed estimates of, for example, $\mathrm{M}_{3} \mathrm{CFT}$.

\subsubsection{Tooth formation times}

We found the average CuDSR of RUD 9 to be $4.4 \mu \mathrm{m} / \mathrm{d}$, far lower than the estimate of 6.5 $\mu \mathrm{m} / \mathrm{d}$ assumed for Anapithecus by Nargolwalla et al. (2005). Our direct measurements of cuspal enamel thickness, combined with the calculated average daily secretion rate, considerably increase the cuspal formation time over previous estimates. It is possible that CuDSR might differ from one tooth type to another, but to resolve this would require additional high resolution cuspal scans for each tooth. We used direct counts of perikymata on the 3D models or of Retzius lines in standardized virtual 2D sections to calculate lateral enamel formation time. In cases where direct calculations were not possible, a back-calculation from age at death (by subtraction of any other available formation times) was performed. We thus present revised crown formation times, but based on one specimen of Anapithecus compared to previous work, of, for example, an $\mathrm{LC}_{1}$ formation time of 737 days rather than 769 days (Nargolwalla et al., 2005).

For root growth, we were able to calculate local (apex) and overall DRERs that yielded mostly smaller values than previous estimates, except for the $M_{1}$ where only an overall measurement of DRER was possible (Table 1). In general, our new data support the fact that 
DRER may change according to tooth locus and also over the course of root growth (Macchiarelli et al., 2006; Dean and Vesey, 2008; Dean and Cole, 2013).

\subsubsection{Initiation, eruption and gingival emergence}

RUD 9 preserves an unerupted permanent canine that we determined to have initiated more than 30 days before birth, contra previous estimates of 30 days after birth (Nargolwalla et al., 2005). Similarly, we found the $M_{1}$ to initiate slightly earlier, at -33 days for the hypoconid and -49 days for the protoconid, both of which are more precocious than the previous estimate of -30 days (Nargolwalla et al., 2005). The $M_{1}$ initiation times we observed for Anapithecus bear marked similarities to other catarrhines, such as monkeys (Swindler and Beynon, 1993) and apes (Beynon et al., 1991; Winkler, 1995; Kuykendall, 1996; Dirks, 1998; Kelley and Schwartz, 2010), in contrast to the values reported for lemurs, for most of which all three molars are initiated prenatally (Schwartz et al., 2002, 2005; Godfrey et al., 2004, 2006; Catlett et al., 2010). In most catarrhines, the $\mathrm{M}_{1}$ is the only permanent tooth to initiate before birth (Oka and Kraus, 1969; Dean and Wood, 1981; Swindler, 1985). In Anapithecus, the canine also initiates before birth (Fig. 4). Because RUD 9 does not preserve any incisors, the overall pattern of eruption and initiation cannot be compared with previous research (Nargolwalla et al., 2005).

We calculated that the RUD $9 \mathrm{RM}_{2}$ initiated 15 days after birth, while Nargolwalla et al. (2005) estimated an initiation at 122 days based on its time of presumed gingival emergence corresponding in time to the canine crown completion (which was more securely determined). Besides the impact of different values for cuspal formation time and periodicity, this difference also stems from the measured $\mathrm{M}_{2}$ root length: Nargolwalla et al. (2005) reported $4 \mathrm{~mm}$ of root on the $\mathrm{M}_{2}$. However, they likely measured root length in the middle of the mesial aspect of the tooth, while our measurement of $\mathrm{RM}_{2}$ root length $(2933 \mu \mathrm{m}$; Table 1) was taken on the developmental section of the protoconid on the buccal side, thus taking into account the corresponding calculated cusp formation time. The impact of this discrepancy is crucial in our calculation: root development does not start exactly at the same time in different points, i.e., at a given time there can be some amount of root already formed on one side of the tooth, while the crown is still developing on another side. We actually used our RFT (thus relying on our root length measurement) that we subtracted together with the $\mathrm{M}_{2}$ CFT from the age at death to calculate the initiation of the $\mathrm{M}_{2}$. Interestingly, the $\mathrm{LP}_{4}$ buccal dentine horn is 1.3 times higher than the MB horn of $\mathrm{RM}_{2}(5145 \mu \mathrm{m}$ versus $3869 \mu \mathrm{m}$; measurements on the developmental 2D sections), and takes 1.3 times longer to grow (502 days versus 367 days). In this context, it is worth recalling that the $\mathrm{P}_{4}$ is still unerupted and lies deep within the corpus and below the LdP $\mathrm{P}_{3}$ roots, while the $\mathrm{M}_{2}$ has almost reached gingival emergence. This pattern of eruption is the most common among Anthropoidea (Swindler and Meekins, 1991; Swindler, 2002).

The $\mathrm{M}_{3}$ initiation is presently documented at 346 days in RUD 9, while Nargolwalla et al. (2005) estimated it to be 493 days. The initiation times for the different teeth reported in this study are even more precocious and closer in time to each other than was estimated by Nargolwalla et al. (2005), especially for the $M_{1}$ and $M_{2}$, which form very early and in rapid succession (Fig. 4). In catarrhines, the overall pattern of initiation reflects the fact that the $M_{1}$ initiates shortly before birth, then the incisors follow shortly afterwards, and the canine starts mineralizing slightly later (see review in Nargolwalla et al., 2005). The absence of any significant delay between the initiation of the anterior teeth and the $\mathrm{M}_{1}$ in Anapithecus is confirmed by the prenatal initiation of the canine (Fig. 4). Given the observation that in all catarrhines for which data are available the canine initiates after the incisors (Swindler, 1985), it is reasonable to conclude that the incisors also initiated before birth in RUD 9, and this is also the typical condition for strepsirrhines (Nargolwalla et al., 2005). This is supported by the observation that two other Anapithecus specimens-RUD 113 and RUD 156-are at the same dental developmental stage as RUD 9, and preserve their incisor crowns, which are fully formed. 
This tends to lend support to a prenatal initiation of the incisors.

Gingival emergence is an important measure of maturation in primates and some further observations about this in Anapithecus are now possible. The $\mathrm{M}_{1}$ must have been the first permanent tooth to erupt, per the widely established eruption pattern in higher primates (e.g., Schultz, 1935). Some attempt can be made to estimate the times of gingival emergence and attainment of functional occlusion, with the most reliable estimates being for $\mathrm{M}_{2}$. If one assumes that the $\mathrm{RM}_{2}$ is actually very close in time to reaching gingival emergence with just $2933 \mu \mathrm{m}$ of root on the mesio-buccal side formed over 317 days, then summed with the $\mathrm{M}_{2}$ protoconid initiation time (15 days postnatally) and its CFT (367 days), this roughly corresponds to functional occlusion at $\sim 2$ years. This is a little more than RUD 9's age at death of 1.9 years. The time taken to erupt from gingival emergence to the level of the occlusal plane is presumed to be short, but is clearly unknowable. Regarding the order in which the permanent canine and third molar would have erupted, our observations would favor an eruption of the canine before the $M_{3}$ as suggested in Kordos and Begun (2001), rather than a simultaneous eruption as proposed in Nargolwalla et al. (2005). In spite of the fact that the fossil does not offer any physical evidence of this, the most parsimonious hypothesis would imply the same order of tooth eruption as seen in most catarrhines (Table 5). The observation of another specimen of $A$. hernyaki, the female RUD 98, which preserves both the lower canines and an $\mathrm{M}_{3}$ at a more advanced developmental stage than RUD 9, adds support to this conclusion. Its $\mathrm{M}_{3}$ s lack any wear facets but these teeth are probably close to gingival emergence (Nargolwalla et al., 2005; confirmed on SOM Fig. S5). RUD $98 \mathrm{M}_{3}$ s have, however, little root formed while the canines have over three quarters of their root formed $(\sim 7 \mathrm{~mm})$, though they also show no sign of any wear. Thus, by the time of death of RUD 98, three quarters of the canine root were formed when the $\mathrm{M}_{3}$ developed a $\sim 4 \mathrm{~mm}$-high crown (see on SOM Fig. S5) and a $\sim 2 \mathrm{~mm}$-long root. The crucial observation in RUD 98 lies in the fact that the canine is well ahead of the $\mathrm{M}_{3}$ in terms of development, and is thus more likely to have been also more advanced in terms of eruption or even achievement of the occlusal plane. RUD 98 does not preserve teeth within the alveolar bone, so their relative position to the alveolar margins in situ remains un- known. Nonetheless, the tooth formation stages strongly suggest that the canine would have erupted first in Anapithecus, as it has over half of its root formed, and the $\mathrm{M}_{3}$ has only $\sim 2 \mathrm{~mm}$ formed (SOM Fig. S5).

Table 5. Pattern of eruption of the permanent canine and M3 in primates, based on the literature.

\begin{tabular}{ll}
\hline Taxon & Source \\
\hline $\begin{array}{l}\text { C emerging before M3 } \\
\text { Extant }\end{array}$ & \\
Pan & (Smith et al., 1994; Kuykendall, 1996; Zihlman et al., 2004) \\
Pongo & (Fooden and Izor, 1983) \\
Macaca & (Smith, 1994; Dean and Leakey, 2004; Van Der Geer and Dermitzakis, 2008) \\
Cercopithecus aethiops (Vervet monkey) & (Bolter and Zihlman, 2003; C erupts before or at the same time as M3) \\
Papio cynocephalus (Baboon) & (Swindler and Meekins, 1991; Dean and Leakey, 2004; Van Der Geer and Dermitzakis, 2008) \\
Mandrillus sphinx & (Van Der Geer and Dermitzakis, 2008) \\
Nasalis & (Harvati and Frost, 2005) \\
Procolobus & (Harvati and Frost, 2005) \\
Prosimians & (Smith et al., 1994) \\
& \\
Fossils & \\
Eurasian Late Miocene Mesopithecus pentelicus & (Harvati and Frost, 2005; Van Der Geer and Dermitzakis, 2008) \\
Pliocene papionin Paradolichopithecus & (Van Der Geer and Dermitzakis, 2008) \\
STS 52 & (Smith et al., 1994) \\
KNM-WT 15000 & (Smith et al., 1994) \\
Anapithecus & (Dean et al., 2003; Dean and Leakey, 2004 [in females]; Harvati and Frost, 2005 “Anapithecus \\
M3 emerging before C & third molars are not always the last teeth to erupt, but appear before the canines in males.") \\
Extant &
\end{tabular}


Colobinae

Most platyrrhines

Pithecia, Cacajao

Fossils

Anapithecus
(Harvati, 2000; Harvati and Frost, 2007; Van Der Geer and Dermitzakis, 2008)

(Smith et al., 1994; Henderson, 2007)

(Smith, 2000 "Schultz's rule”)

(Dean et al., 2003; Dean and Leakey, 2004 [in males]; Harvati and Frost, 2005)

Interestingly, at the time of death, RUD 9 still preserved deciduous premolars with long unresorbed roots, the $\mathrm{dP}_{4}$ being only relatively slightly worn (SOM Fig. S1). Besides, the underlying premolar germs are crown complete, while the M1 is in full occlusion with some moderate wear. The $\mathrm{M}_{2}$ had erupted to a height about the equivalent of gingival emergence and the $\mathrm{P}_{4}$ is still unerupted deep in its crypt. Although this configuration seems characteristic of RUD 9, one cannot definitively say whether the $\mathrm{M}_{2}$ eruption was advanced over the P4 eruption or vice versa in all specimens of Anapithecus. The retention of the deciduous dentition while the molars are reaching gingival emergence close to each other is confirmed by the observations by Kordos and Begun (2001) who also stressed that there was only a subtle difference in stage of wear between the three permanent molars once they are in functional occlusion. All in all, the developmental overlap (initiation and crown formation) between $\mathrm{M}_{1}$ and $\mathrm{M}_{2}$ is greater than previously thought, whereas $M_{3}$ initiates towards the end of $M_{2}$ crown formation. The early initiation of the first two molars close to birth and their following substantial developmental overlap combined with the relatively early eruption of the $\mathrm{M}_{2}$ can be interpreted as evidence of rapid dental development and probably life history.

Relatively late premolar eruption may alternatively represent a strategy to maintain a considerable amount of efficient posterior chewing surface throughout ontogeny with deciduous molars retained as long as they are functionally effective given their smaller size and thinner enamel. Several scholars (Eaglen, 1985; Godfrey et al., 2004) have related the occurrence of two waves of eruption for permanent teeth in lemurs with an adaptation to environmental constraints. The eruption of the anterior molars would coincide with a dietary shift which would require relying more on a folivorous diet (Eaglen, 1985). In the case of Anapithecus, we do see a first wave of dental eruption with the $\mathrm{M}_{1}$ and $\mathrm{M}_{2}$, and later the second wave involving the $\mathrm{P}_{3}, \mathrm{P}_{4}$ and $\mathrm{M}_{3}$ (not necessarily in that order). This strategy of adapting dental eruption to the environmental constraints would match the findings by Deane et al. (2013) suggesting that Anapithecus was primarily frugivorous and would have relied on leaf consumption as a seasonal fall-back. The increased seasonality in the Late Miocene was shown to induce a diversification in dietary adaptations among Miocene hominoids with the combination of feeding on soft and hard fruits (Eastham et al., 2016). Paleoclimatic and isotopic data from R.II at Rudabanya have highlighted a clear seasonality, comparable to a present-day subtropical or at least humid warm temperate climate, with a short-term ripe fruit shortage that would compel Anapithecus and the sympatric hominoid Rudapithecus to rely on harder fruits (Eastham et al., 2016), and Anapithecus on foliage, perhaps to avoid competition between young Anapithecus individuals and Rudapithecus (Deane et al., 2013). It has been further argued that a seasonal environment could exert a strong selective pressure on species to develop fast when the preferred food resources are available and therefore the timing in dental development would be crucial (Harvey and Clutton-Brock, 1985).

Finally, it has been noted that Anapithecus and Rudapithecus, with overlapping body masses and possibly overlapping feeding strategies, may have experienced competitive dietary selection pressure resulting in specialized adaptations in each taxon (Deane et al., 2013). Rapid dental development and rapid growth may indicate that Anapithecus was able to achieve shorter generation times than Rudapithecus, for which there is evidence of a hominid-like extended life history (Smith et al., 2010b). More work on the paleobiology of Anapithecus is needed to work out the adaptive consequences of its pattern of growth and development. 


\subsection{Periodicity and body mass}

We have observed a long-period line periodicity of three days in RUD 9 (Fig. 3). It was on the grounds of a body mass to periodicity correlation that Nargolwalla et al. (2005) favored a periodicity of four days (at most five days) in Anapithecus but rejected a three-day periodicity. Nargolwalla et al.'s (2005) decision was based on Dean and Leakey (2004) who noted the body mass estimate of Victoriapithecus macinnesi, one of the oldest known cercopithecoids (15 Ma), to be $3-5 \mathrm{~kg}$ and that two molars both had a periodicity of three days. Body mass and longperiod line periodicity are assumed to covary in mammals as a result of a common systemic rhythm, although the reasons for intra-group variation remain unclear (Dean, 1995; Dean and Scandrett, 1996). Whether this correlation is positive or negative remains subject to ongoing debates (Smith, 2008; Bromage et al., 2009; Bromage et al., 2016). A factor that may influence the robustness of the correlation between periodicity and body mass is the still poorly documented intraspecific variability in periodicity in some fossil taxa. This has been demonstrated by T.M. Smith et al. (2015: Fig. 2), who reported ranges from six to 12 days in Paranthropus robustus, from six to 11 days in Australopithecus africanus and five to 12 in recent modern humans. Among fossil species, Megaladapis edwardsi has a low periodicity (three days) for a large body mass $(\sim 88 \mathrm{~kg})$, early initiation of its permanent molars, high CuDSR $(\sim 7 \mu \mathrm{m} / \mathrm{d})$ and overall rapid dental development (Schwartz et al., 2005). Similarly, in Palaeopropithecus ingens, a periodicity of two days was found for an animal approaching $45 \mathrm{~kg}$, in combination with accelerated dental development and high CuDSR (Schwartz et al., 2002; Schwartz and Godfrey, 2003). These two examples illustrate that it is possible for large-sized individuals to have a fast pace of development. In addition, low variability in enamel periodicity has been documented in both extant and extinct species of strepsirrhines, together with high variation in related metabolic variables (extant species) and body mass (from a few $\mathrm{kg}$ to $>80 \mathrm{~kg}$; Jungers et al., 2008; Bromage et al., 2009). However, there is also some biomolecular evidence that suggests the control of enamel formation in strepsirrhines may be slightly different since the protein sequence of amelogenin differs to that in other primates, and Lacruz et al. (2011) have argued this might potentially impact on enamel formation rates in this group.

All the above examples reveal how difficult and potentially error-prone it can be in general to estimate a periodicity from an estimated body size. Our findings allow us to revisit the reasoning of Nargolwalla et al. (2005) and provide new evidence of a three-day periodicity in the female holotype RUD 9, the body mass of which, based on orbital area, was estimated to be close to $15 \mathrm{~kg}$ (Kordos and Begun, 2001; Begun, 2002). However, the modal periodicity of Retzius lines in $A$. hernyaki still remains unknown until a larger sample of individuals has been investigated and it remains possible that Anapithecus individuals with four- or five-day periodicities (as proposed by Nargolwalla et al., 2005) would be found in sufficiently large samples. Clearly, however, periodicity estimates within a range of three to four days cannot be rejected on the basis of body size estimates without data from large samples of individuals. Interestingly, when one plots RUD 9 on Figure 3a in Hogg et al. (2015; $\ln$ [periodicity] versus $\ln$ [body mass]), RUD 9 falls right on the strepsirrhine regression line (although this regression does not seem to be significant at $r^{2}=0.05$ ); caution is warranted regarding any of the arguments that have been used previously for estimating enamel periodicities in primates other than by direct observation.

\subsection{Anapithecus dental development in a comparative context}

In comparison with $\mathrm{M}_{2}$ in Victoriapithecus (Dean and Leakey, 2004), for which initiation and gingival emergence have been reported to be 1.95 years apart, this is reduced to less than one year in the Anapithecus $\mathrm{M}_{2}$. Addressing the variability of overlap in CFT in sequential molars on a large radiographic sample of modern humans, Liversidge (2015) has, however, shown that 
the stage of crypt formation is much more variable than that of cusp initiation. She also showed that $M_{3}$ initiation is delayed relative to $M_{2}$ more than $M_{2}$ is to $M_{1}$, as is also observed here in Anapithecus.

Specific comparisons of molar CFTs are difficult but when compared to Ekembo heseloni ${ }^{1}$ (one juvenile [Individual IV, ground section HT3/91G RM2] and one adult [Individual III, ground sections HT2/91C RM1 and HT2/91D RM2]) and Ekembo nyanzae (two adult specimens: RU 1721 RM1 and RU 1695 RM2) (Beynon et al., 1998), RUD 9 completed its crown formation faster. In RUD 9, $\mathrm{C}_{1}$ formed 20\% faster than in E. heseloni and 33-57\% faster than in E. nyanzae. The $\mathrm{P}_{3}, \mathrm{P}_{4}, \mathrm{M}_{1}$ and $\mathrm{M}_{2}$ of RUD 9 respectively formed 22\%, 18\%, 33\%, 29\% faster than those teeth in E. heseloni. Compared to E. nyanzae, the RUD $9 \mathrm{M}_{1}$ formed $60 \%$ faster and the $\mathrm{M}_{2} 57 \%$ faster. Our estimate of crown completion for the RUD $9 \mathrm{M}_{3}$ suggests that formation was 35\% faster than in E. heseloni. While E. heseloni completes the formation of all its permanent crowns before the age of three years (Beynon et al., 1998: Fig. 13), Anapithecus appears to complete all its crowns by just a little more than two years of age (Fig. 4). Further comparison with Oreopithecus bambolii, which has a formation time of 1.96 years for two permanent second molars (Zanolli et al., 2016), indicates again that the molar crowns of Anapithecus form in a considerably shorter amount of time (59\% faster for M1, 49\% for M2 and 44\% for M3).

Unlike Ekembo, for which an increasing gradient in CuDSR has been observed (Table 6), little variation was observed between the inner and outer CuDSR of Anapithecus (Tables 2 and 6). Similar to Victoriapithecus (Zanolli et al., 2016), Anapithecus shows only a 15\% increase from inner to outer enamel CuDSR. The inner CuDSR of RUD 9 is closest to that of Afropithecus turkanensis (17-17.5 Ma; Smith et al., 2003), while the middle CuDSR is most similar to that of Pongo pygmaeus (Dean, 1998), and the outer CuDSR approaches the Pan troglodytes rate (Smith et al., 2007), all reported in a comparative context in Mahoney et al. (2007). The average CuDSR observed in RUD 9 is very close to those observed in a Ouranopithecus macedoniensis M3 (Smith et al., 2004), and to the average rates of $A$. turkanensis and of P. pygmaeus (Mahoney et al., 2007).

Table 6. Cuspal daily secretion rate (CuDSR) of Anapithecus in a comparative context.

\begin{tabular}{|c|c|c|c|c|c|}
\hline Taxon & Inner CuDSR & Middle CuDSR & Outer CuDSR & Average CuDSR & Source \\
\hline $\begin{array}{l}\text { Anapithecus hernyaki } \\
\text { (RUD 9) }\end{array}$ & 3.9 & 4.6 & 4.6 & 4.4 & Present study \\
\hline Ekembo & 4 & & 6 & & Dean and Leakey (2004) \\
\hline Victoriapithecus & 5.65 & & 6.5 & & Dean and Leakey (2004) \\
\hline $\begin{array}{l}\text { Afropithecus } \\
\text { turkanensis }\end{array}$ & $3.97 \pm 0.62$ & & & $4.38 \pm 0.80$ & Smith et al. (2003) \\
\hline Pongo pygmaeus & & $4.65 \pm 0.45$ & & $4.37 \pm 0.36$ & Dean (1998); Mahoney et al. (2007). \\
\hline Pan troglodytes & & & $4.62 \pm 0.49$ & & Smith et al. (2007) \\
\hline $\begin{array}{l}\text { Ouranopithecus } \\
\text { macedoniensis }\end{array}$ & & & & $\begin{array}{l}4.34 \text { (metaconid); } 4.26 \\
\text { (protoconid) }\end{array}$ & Smith et al. (2004) \\
\hline
\end{tabular}

Root extension rates are known to vary during root growth in hominoids but little information exists for other primates. Within a single root, in humans and living great apes, root extension rates reach a peak and then fall off towards root completion. Between teeth, DRERs have also been shown to decrease from M1 to M2 to M3 in recent modern humans and Pan (Dean and Vesey, 2008; Dean, 2010; Dean and Cole, 2013). How roots grow in other primates has remained largely unknown with the exception of a few fossil primates $(O$. bambolii [Zanolli et al., 2016]; V. macinnesi [Dean and Leakey, 2004]; Hispanopithecus laietanus [Dean and Kelley, 2012]). The present study is among the first to provide concrete evidence that root extension is not linear in pliopithecoids, as shown with the DRER of the MB $\mathrm{RM}_{2}$ root, with a cervical rate of

1 Species of Ekembo were formerly included in Proconsul, see McNulty et al. (2015). 
$13.5 \mu \mathrm{m} / \mathrm{d}$, an apical rate of $10.0 \mu \mathrm{m} / \mathrm{d}$ and an overall rate of $9.3 \mu \mathrm{m} / \mathrm{d}$. In addition, rates seem to differ following the same pattern among tooth loci, with higher rates at the cervix $\left(\mathrm{LC}_{1}=12.7\right.$ $\left.\mu \mathrm{m} / \mathrm{d}, \mathrm{RM}_{2} \mathrm{MB}=13.5 \mu \mathrm{m} / \mathrm{d}\right)$ than at the developing root apex $\left(\mathrm{LP}_{4}=10.8 \mu \mathrm{m} / \mathrm{d}, \mathrm{RM}_{2} \mathrm{MB}=10.0\right.$ $\mu \mathrm{m} / \mathrm{d})$.

\section{Conclusions}

The present study explores dental development in the dentition of the Anapithecus holotype RUD 9, using non-destructive synchrotron virtual histology techniques. This suite of techniques empowers dental anthropologists to retrieve a very large amount of information from isolated or in situ teeth belonging to a single individual non-destructively. This analysis of RUD 9 illustrates the benefits of being able to cross-check information between 3D and 2D data. As such it is the first to reach this fine level of detail from a single individual non-destructively.

The fast and precocious nature of Anapithecus dental development has been confirmed in this investigation in a single individual dentition, that of the holotype RUD 9. The permanent first molar and canine initiated over a month before birth. The pattern of eruption of RUD 9, as far as can be determined in a fossil specimen, seems distinctive with respect to $\mathrm{M}_{2}$ and $\mathrm{P}_{4}$, which have the same amount of root formed, while the $\mathrm{P}_{4}$ still lies deep in its crypt below the unexfoliated deciduous premolars, and the $\mathrm{M}_{2}$ is close to gingival emergence. We conclude that the $\mathrm{P}_{4}$ erupted much later than the $\mathrm{M}_{2}$ relative to other catarrhines, possibly to increase the functional lifespan of the chewing surfaces in newly weaned individuals. Anapithecus appears to retain a very primitive pattern, closer to strepsirrhines than anthropoids, with early and fast development and persistence of deciduous molars in a mixed dentition that includes a nearly complete $\mathrm{M}_{3}$ crown. Our analysis suggests that the pliopithecoids, represented by Anapithecus, preserve many aspects of the ancestral morphology of the catarrhines in terms of dental development (e.g., fast dental development, early initiation especially of the canine and probably the incisors, $\mathrm{M}_{1}$ and $\mathrm{M}_{2}$ ). Although they are stem catarrhines, they are also representatives of a long lineage dating back to at least $30 \mathrm{Ma}$, but one that only appears in the fossil record at about $15 \mathrm{Ma}$ in Europe, and possibly earlier in Asia (Harrison et al., 1991; Begun, 2002). It is possible therefore that Anapithecus had derived characters not found in older stem catarrhines. For example, it is likely that certain aspects of dental development in Anapithecus represent adaptations specific to diet, competition, predation or other selection pressures unique to this portion of the pliopithecoid radiation.

Given that dental development in Anapithecus more closely resembles that of lemurs than does the dental development of any other catarrhine, we suggest that the condition we have identified in Anapithecus may be primitive for catarrhines. Drawing further conclusions at this point is speculative but the suggestion must be that growth in Anapithecus was in general fast and quite different to that of the sympatric hominoid Rudapithecus known from the same localities.

\section{Acknowledgements}

We are grateful to Ildiko Pap, Head of Department, and Sandor Evinger, assistant curator, Department of Anthropology, the Hungarian Museum of Natural History and to the excavation team of the R.II site. We gratefully acknowledge the considerable contribution to this project of Paul Tafforeau and for access to beamtime on ID 19 at the ESRF, tomographic data acquisition and processing, and especially his input during the early stages of this study. We thank Tanya M. Smith for her involvement in the initiation of this project, Matthew Skinner for performing the 
mCT acquisitions of the RUD 98 teeth at MPI-EVA, and David Plotzki for technical assistance at MPI-EVA. Our gratitude goes to Rodrigo Lacruz, Holly Smith, Gary Schwartz, Helen Liversidge and Clement Zanolli for fruitful discussions. We are extremely grateful to Sarah Elton (Editor), and to the Associate Editor for their time and effort in considerably improving this manuscript. We also thank the three reviewers for their detailed comments. This research was funded by the Max Planck Society, the ESRF and NSERC.

\section{Supplementary Online Material}

Supplementary online material related to this article can be found at http://dx.doi.org/10.1016/j.jhevol.2017.03.007 .

\section{References}

Begun, D., 2002. The Pliopithecoidea. In: Hartwig, W.C. (Ed.), The Primate Fossil Record. Cambridge University Press, Cambridge, UK, pp. 221-240.

Begun, D.R., 1989. A large pliopithecine molar from Germany and some notes on the Pliopithecinae. Folia Primatol. 52, 156-166.

Beynon, A.D., Dean, M.C., Reid, D.J., 1991. Histological study on the chronology of the developing dentition in gorilla and orangutan. Am. J. Phys. Anthropol. 86, 189-203.

Beynon, A.D., Dean, M.C., Leakey, M.G., Reid, D.J., Walker, A., 1998. Comparative dental development and microstructure of Proconsul teeth from Rusinga Island, Kenya. J. Hum. Evol. 35, 163-209.

Bolter, D.R., Zihlman, A.L., 2003. Morphometric analysis of growth and development in wildcollected vervet monkeys (Cercopithecus aethiops), with implications for growth patterns in Old World monkeys, apes and humans. J. Zool. 260, 99-110.

Bromage, T., Lacruz, R., Hogg, R., Goldman, H., McFarlin, S., Warshaw, J., Dirks, W., Perez-Ochoa, A., Smolyar, I., Enlow, D., Boyde, A., 2009. Lamellar bone is an incremental tissue reconciling enamel rhythms, body size, and organismal life history. Calcif. Tissue Int. 84, 388-404.

Bromage, T.G., Juwayeyi, Y.M., Katris, J.A., Gomez, S., Ovsiy, O., Goldstein, J., Janal, M.N., Hu, B., Schrenk, F., 2016. The scaling of human osteocyte lacuna density with body size and metabolism. C. R. Palevol. 15, 32-39.

Catlett, K.K., Schwartz, G.T., Godfrey, L.R., Jungers, W.L., 2010. "Life history space": A multivariate analysis of life history variation in extant and extinct Malagasy lemurs. Am. J. Phys. Anthropol. 142, 391-404.

Deane, A.S., Nargolwalla, M.C., Kordos, L., Begun, D.R., 2013. New evidence for diet and niche partitioning in Rudapithecus and Anapithecus from Rudabanya, Hungary. J. Hum. Evol. 65, 704714.

Dean, M.C., 1995. The nature and periodicity of incremental lines in primate dentine and their relationship to periradicular bands in OH 16 (Homo habilis). In: Moggi-Cecchi, J. (Ed.), Aspects of Dental Biology: Palaeontology, Anthro- pology and Evolution. International Institute for the Study of Man, Florence, pp. 239-265.

Dean, M.C., 1998. A comparative study of cross striation spacings in cuspal enamel and of four methods of estimating the time taken to grow molar cuspal enamel in Pan, Pongo and Homo. J. Hum. Evol. 35, 449-462.

Dean, M.C., 2010. Retrieving chronological age from dental remains of early fossil hominins to reconstruct human growth in the past. Philos. T. Roy. Soc. B 365, 3397-3410.

Dean, M.C., 2012. A histological method that can be used to estimate the time taken to form the crown of a permanent tooth. In: Bell, L.S. (Ed.), Forensic Microscopy for Skeletal Tissues: Methods and Protocols. Springer Science and Business Media, New York, pp. 89-100.

Dean, M.C., Cole, T.J., 2013. Human life history evolution explains dissociation between the timing 
of tooth eruption and peak rates of root growth. PLOS ONE 8, e54534.

Dean, M.C., Kelley, J., 2012. Comparative dental development in Hispanopithecus laietanus and Pan troglodytes. J. Hum. Evol. 62, 174-178.

Dean, M.C., Leakey, M.G., 2004. Enamel and dentine development and the life history profile of Victoriapithecus macinnesi from Maboko Island, Kenya. Ann. Anat. - Anat. Anz. 186, 405-412.

Dean, M.C., Scandrett, A.E., 1996. The relation between long-period incremental markings in dentine and daily cross-striations in enamel in human teeth. Arch. Oral Biol. 41, 233-241.

Dean, M.C., Vesey, P., 2008. Preliminary observations on increasing root length during the eruptive phase of tooth development in modern humans and great apes. J. Hum. Evol. 54, 258271.

Dean, M.C., Wood, B.A., 1981. Developing pongid dentition and its use for ageing individual crania in comparative cross-sectional growth studies. Folia Primatol. 36, 111-127.

Dean, M.C., Begun, D.R., Reid, D.R., Nargolwalla, M.C., Kordos, L., 2003. Dental development in Anapithecus. Am. J. Phys. Anthropol. 120, 85.

Dirks, W., 1998. Histological reconstruction of dental development and age at death in a juvenile gibbon (Hylobates lar). J. Hum. Evol. 35, 411-425.

Eaglen, R.H., 1985. Behavioral correlates of tooth eruption in Madagascar lemurs. Am. J. Phys. Anthropol. 66, 307-315.

Eastham, L.C., Feranec, R.S., Begun, D.R., 2016. Stable isotopes show resource partitioning among the early Late Miocene herbivore community at Rudabanya II: Paleoenvironmental implications for the hominoid, Rudapithecus hungaricus. Palaeogeogr. Palaeoclimatol. Palaeoecol. 454, 161-174.

Eronen, J.T., Rook, L., 2004. The Mio-Pliocene European primate fossil record: dynamics and habitat tracking. J. Hum. Evol. 47, 323-341.

Fooden, J., Izor, R.J., 1983. Growth curves, dental emergence norms, and supplementary morphological observations in known-age captive orangutans. Am. J. Primatol. 5, 285-301.

Godfrey, L.R., Samonds, K.E., Jungers, W.L., Sutherland, M.R., Irwin, M.T., 2004.

Ontogenetic correlates of diet in Malagasy lemurs. Am. J. Phys. Anthropol. 123, 250-276.

Godfrey, L.R., Samonds, K.E., Wright, P.C., King, S.J., 2005. Schultz's unruly rule: dental developmental sequences and schedules in small-bodied, folivorous lemurs. Folia Primatol. 76, 77-99.

Godfrey, L.R., Schwartz, G.T., Samonds, K.E., Jungers, W.L., Catlett, K.K., 2006. The secrets of lemur teeth. Evol. Anthropol. Issues News Rev. 15, 142-154.

Harrison, T., 2013. Catarrhine origins. In: Begun, D.R. (Ed.), A Companion to Paleoanthropology. Wiley-Blackwell, Chichester, pp. 376-396.

Harrison, T., Delson, E., Jian, G., 1991. A new species of Pliopithecus from the middle Miocene of China and its implications for early catarrhine zoogeography. J. Hum. Evol. 21, 329-361.

Harvati, K., 2000. Dental eruption sequence among colobine primates. Am. J. Phys. Anthropol. 112, 69-85.

Harvati, K., Frost, S.R., 2005. Dental eruption sequence in Mesopithecus pentelicus. Acta Palaeontol. Romaniae 5, 205-210.

Harvati, K., Frost, S.R., 2007. Dental eruption sequences in fossil colobines and the evolution of primate life histories. Int. J. Primatol. 28, 705-728.

Harvey, P.H., Clutton-Brock, T.H., 1985. Life history variation in primates. Evolution 39, 559-581.

Henderson, E., 2007. Platyrrhine dental eruption sequences. Am. J. Phys. Anthropol. 134, 226239.

Hogg, R.T., Godfrey, L.R., Schwartz, G.T., Dirks, W., Bromage, T.G., 2015. Lemur biorhythms and life history evolution. PLOS ONE 10, e0134210.

Jungers, W.L., Demes, B., Godfrey, L.R., 2008. How big were the "giant" extinct lemurs of Madagascar? In: Fleagle, J.G., Gilbert, C.C. (Eds.), Elwyn Simons: A Search for Origins. Springer, New York, pp. 343-360. 
Kelley, J., Schwartz, G.T., 2010. Dental development and life history in living African and Asian apes. Proc. Natl. Acad. Sci. 107, 1035-1040.

Kordos, L., Begun, D.R., 2001. Primates from Rudabanya: allocation of specimens to individuals, sex and age categories. J. Hum. Evol. 40, 17-39.

Kordos, L., Begun, D.R., 2002. Rudabanya: A late Miocene subtropical swamp deposit with evidence of the origin of the African apes and humans. Evol. Anthropol. Issues News Rev. 11, 45-57.

Kretzoi, M., 1975. New ramapithecines and Pliopithecus from the Lower Pliocene of Rudabanya in north-eastern Hungary. Nature 257, 578-581.

Kuykendall, K.L., 1996. Dental development in chimpanzees (Pan troglodytes): The timing of tooth calcification stages. Am. J. Phys. Anthropol. 99, 135-157.

Lacruz, R.S., Lakshminarayanan, R., Bromley, K.M., Hacia, J.G., Bromage, T.G., Snead, M.L., MoradianOldak, J., Paine, M.L., 2011. Structural analysis of a repetitive protein sequence motif in strepsirrhine primate amelogenin. PloS ONE 6, e18028.

Le Cabec, A., Tang, N.K., Tafforeau, P., 2015. Accessing developmental information of fossil hominin teeth using new synchrotron microtomography-based visualization techniques of dental surfaces and interfaces. PLOS ONE 10, e0123019.

Liversidge, H.M., 2015. Human molar formation overlap. Am. J. Phys. Anthropol. 156, 205.

Macchiarelli, R., Bondioli, L., Debenath, A., Mazurier, A., Tournepiche, J.-F., Birch, W., Dean, M.C., 2006. How Neanderthal molar teeth grew. Nature 444, 748-751.

Mahoney, P., Smith, T.M., Schwartz, G.T., Dean, C., Kelley, J., 2007. Molar crown formation in the Late Miocene Asian hominoids, Sivapithecus parvada and Sivapithecus indicus. J. Hum. Evol. 53, 61-68.

McNulty, K.P., Begun, D.R., Kelley, J., Manthi, F.K., Mbua, E.N., 2015. A systematic revision of Proconsul with the description of a new genus of early Miocene hominoid. J. Hum. Evol. 84, 42-61.

Nargolwalla, M.C., Begun, D.R., Dean, M.C., Reid, D.J., Kordos, L., 2005. Dental development and life history in Anapithecus hernyaki. J. Hum. Evol. 49, 99-121.

Oka, S.W., Kraus, B.S., 1969. The circumnatal status of molar crown maturation among the hominoidea. Arch. Oral Biol. 14, 639-659.

Pozzi, L., Hodgson, J.A., Burrell, A.S., Sterner, K.N., Raaum, R.L., Disotell, T.R., 2014. Primate phylogenetic relationships and divergence dates inferred from complete mitochondrial genomes. Mol. Phylogenet. Evol. 75, 165-183.

Raaum, R.L., 2015. Molecular evidence on primate origins and evolution. In: Henke, W., Tattersall, I. (Eds.), Handbook of Paleoanthropology. Springer-Verlag, Berlin, Heidelberg, pp. 1083-1135.

Schultz, A.H., 1935. Eruption and decay of the permanent teeth in primates. Am. J. Phys. Anthropol. 19, 489-581.

Schwartz, G.T., Godfrey, L.R., 2003. Box 3. Big bodies, fast teeth. Evol. Anthropol. 12, 259.

Schwartz, G.T., Samonds, K.E., Godfrey, L.R., Jungers, W.L., Simons, E.L., 2002. Dental microstructure and life history in subfossil Malagasy lemurs. Proc. Natl. Acad. Sci. 99, 6124-6129.

Schwartz, G.T., Mahoney, P., Godfrey, L.R., Cuozzo, F.P., Jungers, W.L., Randria, G.F.N., 2005. Dental development in Megaladapis edwardsi (Primates, Lemuriformes): Implications for understanding life history variation in subfossil lemurs. J. Hum. Evol. 49, 702-721.

Schwartz, G.T., Godfrey, L.R., Mahoney, P., 2007. Inferring primate growth, development and life history from dental microstructure: the case of the extinct Malagasy lemur, Megaladapis. In: Bailey, S.E., Hublin, J.-J. (Eds.), Dental Perspectives on Human Evolution: State of the Art Research in Dental Paleoanthropology. Springer, Netherlands, pp. 147-162.

Smith, B.H., 1994. Sequence of emergence of the permanent teeth in Macaca, Pan, Homo, and Australopithecus: Its evolutionary significance. Am. J. Hum. Biol. 6, 61-76.

Smith, B.H., 2000. 15 - "Schultz"s Rule' and the evolution of tooth emergence and replacement patterns in primates and ungulates. In: Teaford, M.F., Smith, M.M., Ferguson, M.W. (Eds.), Development, Function and Evolution of Teeth, pp. 212-227.

Smith, B.H., Crummett, T.L., Brandt, K.L., 1994. Ages of eruption of primate teeth: A compendium for aging individuals and comparing life histories. Am. J. Phys. Anthropol. 37, 177-231. 
Smith, T.D., Muchlinski, M.N., Jankord, K.D., Progar, A.J., Bonar, C.J., Evans, S., Williams, L., Vinyard, C.J., Deleon, V.B., 2015. Dental maturation, eruption, and gingival emergence in the upper jaw of newborn primates. Anat. Rec. 298, 2098-2131.

Smith, T.M., 2008. Incremental dental development: Methods and applications in hominoid evolutionary studies. J. Hum. Evol. 54, 205-224.

Smith, T.M., Martin, L.B., Leakey, M.G., 2003. Enamel thickness, microstructure and development in Afropithecus turkanensis. J. Hum. Evol. 44, 283-306.

Smith, T.M., Martin, L.B., Reid, D.J., de Bonis, L., Koufos, G.D., 2004. An examination of dental development in Graecopithecus freybergi (= Ouranopithecus macedoniensis). J. Hum. Evol. 46, 551577.

Smith, T.M., Reid, D.J., Dean, M.C., Olejniczak, A.J., Martin, L.B., 2007. Molar devel- opment in common chimpanzees (Pan troglodytes). J. Hum. Evol. 52, 201-216.

Smith, T.M., Tafforeau, P., Reid, D.J., Pouech, J., Lazzari, V., Zermeno, J.P., Guatelli- Steinberg, D., Olejniczak, A.J., Hoffman, A., Radovkic, J., Makaremi, M., Toussaint, M., Stringer, C., Hublin, J.-J., 2010 a. Dental evidence for ontogenetic differences between modern humans and Neanderthals. Proc. Natl. Acad. Sci. 107, 20923-20928.

Smith, T.M., Zermeno, J.P., Pouech, J., Tafforeau, P., Olejniczak, A.J., Reid, D.J., Eastham, L., Hublin, J.-J., Kordos, L., Begun, D., 2010b. Enamel thickness and tooth development in a subadult Dryopithecus brancoi (Rudapithecus hungaricus) individual. Am. J. Phys. Anthropol. 141, 220.

Smith, T.M., Tafforeau, P., Le Cabec, A., Bonnin, A., Houssaye, A., Pouech, J., Moggi- Cecchi, J., Manthi, F., Ward, C., Makaremi, M., Menter, C.G., 2015. Dental ontogeny in Pliocene and early Pleistocene hominins. PLOS ONE 10, e0118118.

Steiper, M.E., Seiffert, E.R., 2012. Evidence for a convergent slowdown in primate molecular rates and its implications for the timing of early primate evolution. Proc. Natl. Acad. Sci. 109, 60066011.

Sukselainen, L., Fortelius, M., Harrison, T., 2015. Co-occurrence of pliopithecoid and hominoid primates in the fossil record: An ecometric analysis. J. Hum. Evol. 84, 25-41.

Swindler, D.R., 1985. Nonhuman primate dental development and its relationship to human dental development. In: Watts, E.S. (Ed.), Nonhuman Primate Models for Human Growth and Development. Alan R. Liss, New York, pp. 67-94.

Swindler, D.R., 2002. Primate Dentition: An Introduction to the Teeth of Non- human Primates. Cambridge University Press, Cambridge.

Swindler, D.R., Beynon, A.D., 1993. The development and microstructure of the dentition of Theropithecus. In: Jablonski, N.G. (Ed.), Theropithecus: The Rise and Fall of a Primate Genus. Cambridge University Press, Cambridge, UK, pp. 351-381.

Swindler, D.R., Meekins, D., 1991. Dental development of the permanent mandibular teeth in the baboon, Papio cynocephalus. Am. J. Hum. Biol. 3, 571-580.

Tafforeau, P., Boistel, R., Boller, E., Bravin, A., Brunet, M., Chaimanee, Y., Cloetens, P., Feist, M., Hoszowska, J., Jaeger, J.J., 2006. Applications of X-ray synchrotron microtomography for nondestructive 3D studies of paleontological specimens. Appl. Phys. Mater. Sci. Process 83, 195-202.

Van Der Geer, A.A., Dermitzakis, M.D., 2008. Dental eruption sequence in the Pliocene papionin Paradolichopithecus arvernensis (Mammalia: Primates) from Greece. J. Vertebr. Paleontol. 28, 1238-1244.

Winkler, L.A., 1995. A comparison of radiographic and anatomical evidence of tooth development in infant apes. Folia Primatol. 65, 1-13.

Zabler, S., Riesemeier, H., Fratzl, P., Zaslansky, P., 2006. Fresnel-propagated imaging for the study of human tooth dentin by partially coherent x-ray tomography. Opt. Express 14, 8584-8597.

Zanolli, C., Dean, C., Rook, L., Bondioli, L., Mazurier, A., Macchiarelli, R., 2016. Enamel thickness and enamel growth in Oreopithecus: Combining microtomographic and histological evidence. C. R. Palevol. 15, 217-234.

Zihlman, A., Bolter, D., Boesch, C., 2004. Wild chimpanzee dentition and its implications for assessing life history in immature hominin fossils. Proc. Natl. Acad. Sci. 101, 10541-10543. 